\title{
Location Based Services Acceptance and Adoption Evaluation: An Investigation on Mobile Phone Users' Response to Awareness and Utilization of LBS Technology in Nairobi Kenya
}

\author{
Charles Busera Wasomi ${ }^{*}$, Edward Hunja Waithaka1, Moses Karoki Gachari², \\ David Ndegwa Kuria ${ }^{2}$
}

\footnotetext{
${ }^{1}$ Department of Geomatics Engineering and Geospatial Information Systems, Jomo Kenyatta University of Agriculture and Technology (JKUAT), Nairobi, Kenya

${ }^{2}$ Department of Geomatics Engineering and Geospatial Information Systems, Dedan Kimathi University of Technology (DKUT), Nyeri, Kenya

Email: *cbwasomi@gmail.com
}

\begin{abstract}
How to cite this paper: Wasomi, C.B., Waithaka, E.H., Gachari, M.K. and Kuria, D.N. (2021) Location Based Services Acceptance and Adoption Evaluation: An Investigation on Mobile Phone Users' Response to Awareness and Utilization of LBS Technology in Nairobi Kenya. Journal of Computer and Communications, 9, 60-96. https://doi.org/10.4236/jcc.2021.910005
\end{abstract}

Received: July 14, 2021

Accepted: October 15, 2021

Published: October 18, 2021

Copyright ( 2021 by author(s) and Scientific Research Publishing Inc. This work is licensed under the Creative Commons Attribution International License (CC BY 4.0).

http://creativecommons.org/licenses/by/4.0/ (c) (i) Open Access

\begin{abstract}
Location Based Navigation System (LBNS) is a specific Location Based Service (LBS) purely for navigational purpose. These systems resolve position of a user by using GNSS/GPS positioning technologies, to which supplementary information on goods and services are tagged. The navigation services have become popular and can be installed on mobile phones to provide route information, location of points of interest and user's current location. LBS has continued to face challenges which include "communication" process towards user reference. Location Based Service System conveys suitable information through a mobile device for effective decision making and reaction within a given time span. This research was geared at understanding the state of LBS technology acceptance and adoption by users in Nairobi Kenya. To do this a quantitative study was carried out through a questionnaire, to investigate mobile phone users' response on awareness and use of LBS technology. Testing the growth of this technology in this region compared to predictions in previous studies using Technology Acceptance Model (TAM), it is evident that many users may be aware of GPS functionality in mobile phones but are certainly yet to fully embrace the technology as they rarely use it. This points to some underlying challenges towards this technology within this part of the World, thereby recommending for deliberate monitoring and evaluation of
\end{abstract}


LBS technology for sustenance growth based on user satisfaction and acceptance for improved usability.

\section{Keywords}

Location Based Services (LBS), Smartphone, Mobile Device, Mobile Phone, Location Based Navigation Service (LBNS), Technology Acceptance Model, Quantitative Analysis

\section{Introduction}

\subsection{Background}

Technology is dynamic and its importance is inevitable in our day to day lives; it brings together tools to promote development, usage, and information exchange, making tasks easier and solving many problems for mankind [1]. In the last decade paper map has given way to digital format in electronic devices, where a lot of information and data are tagged to location in digital maps, of which many are accessed through screens of mobile devices [2]. Recently, digital maps have become more than just visualization tools in navigation systems, and now utilize the processing power found on mobile devices to provide users with additional navigational and routing information tailored to user's needs, hence birth of Location Based Services [3] [4].

Previous studies predicted exponential growth in LBS technology over the world [5] [6] [7] [8]. This was supported by a survey where Google Maps (Google Inc., USA), an LBNS application, was ranked top smart phone mobile application in use in the USA as shown in Figure 1. LBNS, as with any other technology, is an application of scientific knowledge developed for practical purposes in applied sciences, geared to benefit and make it easy for end user [9]. Therefore, end users determine the acceptability and adoption of any technology if they choose to embrace it [10]. Technology can be accepted or rejected, and

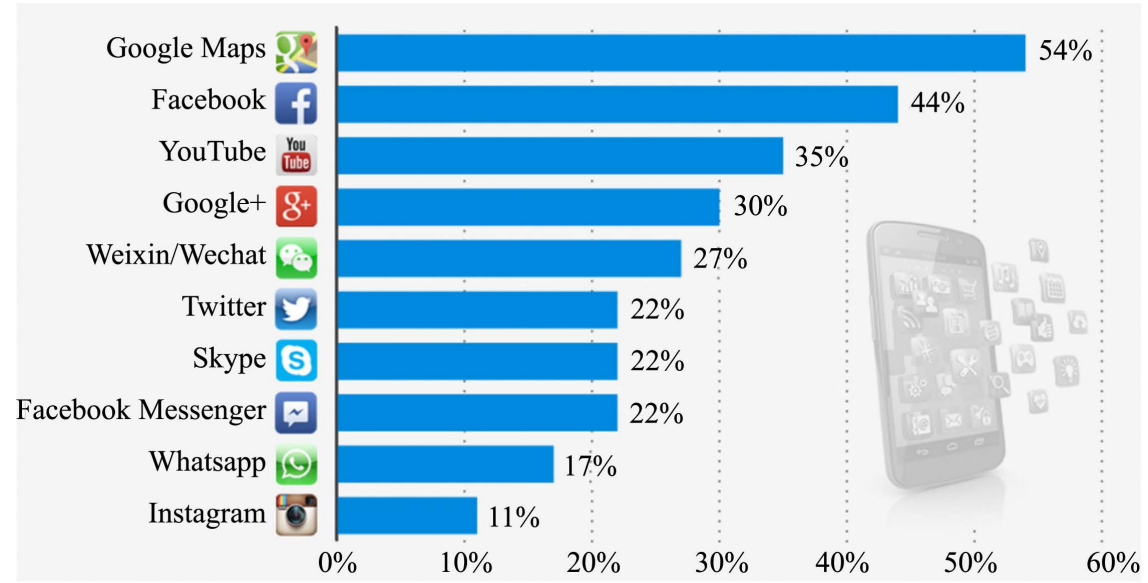

Figure 1. Mobile phone application rating (Global web index, 2013). 
with rapid growth of LBNS in other parts of the world as predicted. This paper tests the hypothesis that the same holds true for Nairobi, Kenya. The research adopted a Technology Acceptance Modeling (TAM) technic to assess this hypothesis [11], with a quantitative study carried out in Nairobi, Kenya.

\subsection{System Components}

LBNS is a specific Location Based Service purely for navigational purpose [12]. The architecture of these applications is a six-tier, comprising user, geographic data/spatial data, mobile device, telecommunication service, Internet, and GNSS/GPS systems [13] as illustrated in Figure 2.

The users of these systems are not only the holder of mobile phones, but also companies such as Uber who use LBNS for their operations. These are end consumers of information that is stored, shared, analyzed, and distributed by the system. Geospatial data forms a very important component in the architecture too, forming a backbone of these systems as every information and feature on/over/underneath the earth surface is spatially defined with respect to the earth. One cannot provide competent LBNS without good spatial data infrastructure [14] [15]. Geospatial data is information that identifies geographic location of features and boundaries on Earth, such as natural or constructed features, oceans, and more. Spatial data is usually stored as coordinates and topology and is data that can be mapped having an implicit or explicit association with a location relative to the Earth. Mobile device is another key component of these systems. A mobile device (or handheld computer) is a computing device small enough to hold and operate in one's hand [16]. Many mobile devices have decent processing power, with some as powerful as mid-range laptops. These mobile devices can process data fast and render map images seamlessly. Typically,

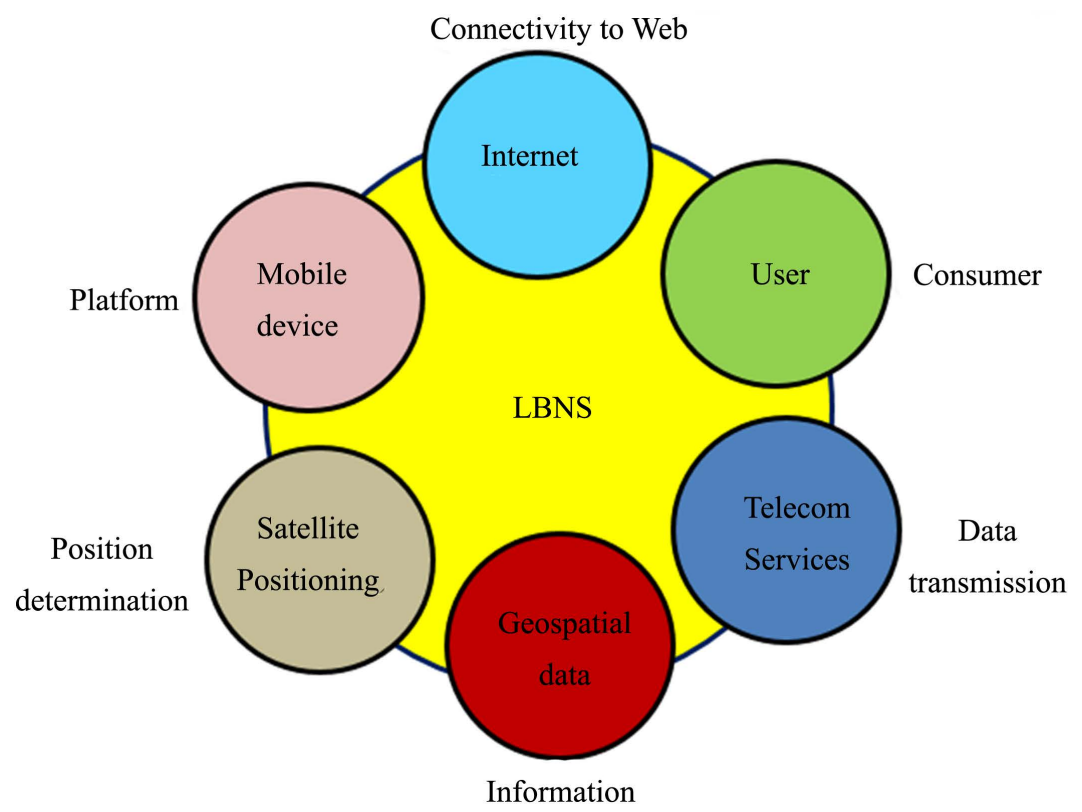

Figure 2. Components of LBNS. 
any handheld computer device will have an LCD flat screen interface, providing a touchscreen interface with digital buttons and keyboard or physical buttons along with a physical keyboard [17]. Many such devices can connect to the Internet and interconnect with other devices such as car entertainment systems or headsets via Wi-Fi, Bluetooth, cellular networks or Near Field Communication (NFC) [18]. Telecommunication service is an important element in LBNS, it is a means of exchange of information/data by electronic and electrical means within a wide area of coverage [19]. It enables connection of computers anywhere in the world via dedicated routers and servers. A complete telecommunication arrangement is made up of two or more stations equipped with transmitter and receiver devices, which transmits signs, signals, messages, words, writings, images and sounds or information of any nature by wire, radio, optical systems, internet, such are computer networks that use Internet protocol suite (TCP/IP) [20]. Internet connection is an equally vital part of the architecture, this transmits and receives all kinds of information such as text, graphics, voice, video, and computer applications [21]. The connectivity options available include 3G, $4 \mathrm{G}, 5 \mathrm{G}$, and Wi-Fi, and these have all helped the growth of LBNS [22]. Navigation applications have become popular being able to be installed in mobile phones to provide direction, location of point of interest and user position [23], GNSS/GPS systems have provided autonomous geo-spatial position of a handheld device with global coverage where they use satellites to deliver geo-spatial position [24]. They allow small electronic receivers to determine their location (longitude, latitude, and altitude/elevation) to high precision (within a few meters) using time signals transmitted along a line of sight by radio from satellites. The system can be used for providing position, navigation or for tracking position of something fitted with a receiver (satellite tracking). Geographical communication utility such as GPRS and GPS are deployed as part of the LBS system [25]. GNSS/GPS, complimented by GPRS navigation solutions help give accurate information on user's location, and this supports LBNS resolve distance to services and utilities, and help optimize routing information [26]. These systems resolve position of a user by using GNSS/GPS positioning technologies, to which auxiliary data on facilities and services are attached [27]. According to Garg et al. (2013), the ability to incorporate geographical positioning elements in mobile systems has in a greater way boosted advancement in the use of LBS in smartphones [28]. This is also supported by Deidda et al. (2013) who stated that LBS depend on geographic positioning to reveal information to users [29].

\subsection{LBS Challenges}

Even though LBS development has grown exponentially, challenges continue to exist [30]. Basiri et al. (2016) acknowledge on the existence of these LBS challenges and categorize them into "technical and non-technical" [31]. With technical comprising: positioning, cost of service, location privacy, power consumption, user interface, whereas non-technical comprise social acceptance, commercial and business model, privacy concerns, human factors, and cultural differ- 
ences, all which solutions can be achieved through scientific investigations. Among the existing challenges in LBS is "communication" process on a user point of view where Location Based Service system convey suitable information through smartphone (mobile device) for effective decision making and reaction within a given time span [30].

Mobile phone is a telephone which access cellular radio system within a wide area, without physical connection to a network [32]. Mobile phones can be used for a variety of purposes, including making voice calls, business transactions, gathering information through radio and television broadcast, for money transfer and banking among other services [33] [34] [35]. Mobile phones have evolved from basic cellular phone with limited processing capacity to smart phone which are characterized by greater processing capacity, sophisticated operating systems, and the ability to host many applications including LBS applications [36]. Smart phones often have larger screens that enable better viewing of content, including maps and images rendered by LBS.

\subsection{Technology Acceptance and Adoption (TAA)}

Technology acceptance and adoption is a measure of whether end users embrace the subject technology by utilizing it for their tasks indicating how valuable the technology is perceived. TAA is important for further development of any new technology to facilitated improvement efficiency, service delivery and realize value for money [37]. Several theories have been proposed to explain consumer acceptance of new technologies and their intention to use it [38], these include the Theory of Diffusion of Innovations (DIT), which could measure on innovation through certain period of time within a social system [39]. Theory of Task Technology-Fit (TTF), emphasizes on efficiency, effectiveness, and quality of technology innovation [40]. Theory of Reasonable Action (TRA), considers how technology molds the user behavior towards the technology [41]. Theory of Planned Behavior (TPB), deals with the control behavior that is perceived to have been introduced by the technology [42] [43]. Decomposed Theory of Planned Behaviour is subject to norms and perceived behavior and is normally used for products that exist in the market [44]. Technology Acceptance Model (TAM) is specially tailed for modelling user acceptance on information systems or technologies gauged on potential users' perceived usefulness of the technology [45]. Technology Acceptance Model 2 (TAM2) considers social norms for a newly developed technology through pre-implementation to post-implementation [46], whereas Technology Acceptance Model 3 (TAM 3) considers system characteristics, social influence and facilitating condition [38] [47].

This research chose to utilize TAM for measuring acceptance and adoption of LBS technology based on the fact that the target population was based on utilization of mobile phones and not LBS the sample population thereby was considered as potential users of LBS technology. In TAM perceived use and perceived usefulness is considered as contributor to individual's intention to use this technology, hence provides a general framework as indicated in Figure 3, that can 


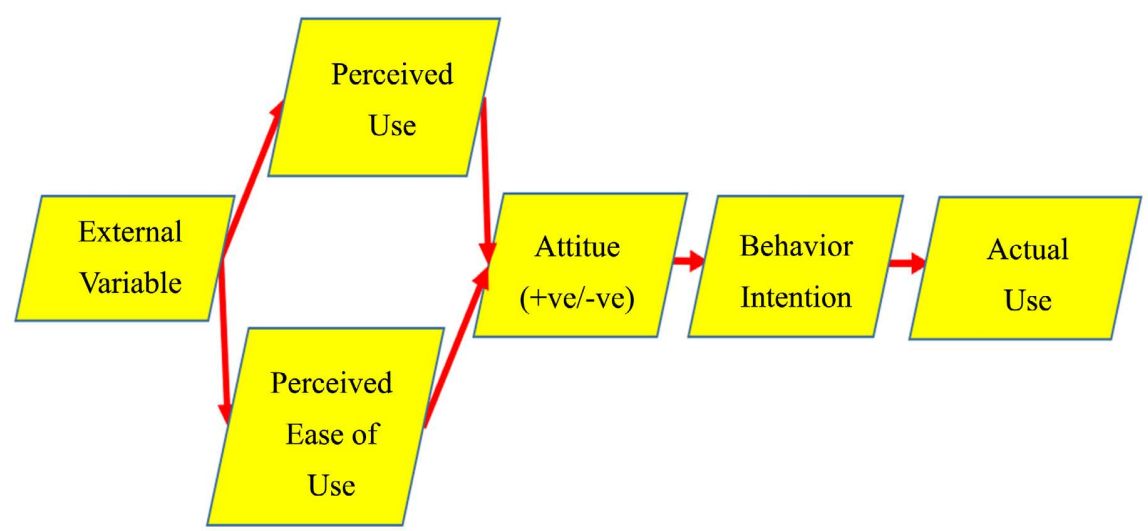

Figure 3. Technology acceptance model factors.

easily related to factors that impact on use of novel technology, as compared to other models [48].

\subsection{Aim of Paper}

This paper was aimed at testing the hypothesis that "LBS technology was to have a rapid growth worldwide", that was presumably to mean that this technology acceptance and adoption would be high, proportionate with awareness and actual usage. Based on this, the paper was to investigate and determine through mobile phone users in Nairobi, Kenya utilizing Technology Acceptance Model (TAM) to determine whether the null hypothesis holds true or not.

\section{Methodology}

\subsection{Study Area}

Nairobi, Kenya's capital city, was chosen for the study. Nairobi, laying at $1^{\circ} 09^{\prime} \mathrm{S}$ $36^{\circ} 39^{\prime} \mathrm{E}$ and $1^{\circ} 27^{\prime} \mathrm{S} 37^{\circ} 06^{\prime} \mathrm{E}$ in the eastern part of Africa as shown in Figure 4. It occupies 696 square kilometers and has a population of 3.1 million [49]. Currently it has a population of about 4.397 million people [50]. Nairobi is Kenya's commercial, transport, communication, and administrative center. It also serves as a transport corridor to the northern states of Sudan, Ethiopia to Egypt. It links to western and central African through Uganda, Rwanda, Burundi and Democratic Republic of Congo. It also links to western and central African countries of Uganda, Burundi, Rwanda, and Democratic Republic of Congo. To the east it connects to the Republic of Somalia, whereas to the southern states through Tanzania all the way to South Africa as well as to Mombasa port in the southern part of Kenya. It links flight services to major destinations throughout the world and has train services to Uganda and Southern Sudan which is still under construction. Nairobi city is split into eight divisions, namely Makadara, Kamukunji, Starehe, Lang'ata, Dagoretti, Westlands, Kasarani and Embakasi. Nairobi's Central Business District falls in Starehe Division [49], and is the main transport and communication node for Nairobi County as shown in Figure 5, as well as the whole country. It is estimated that 2.2 million people in Nairobi $(70 \%$ of the 


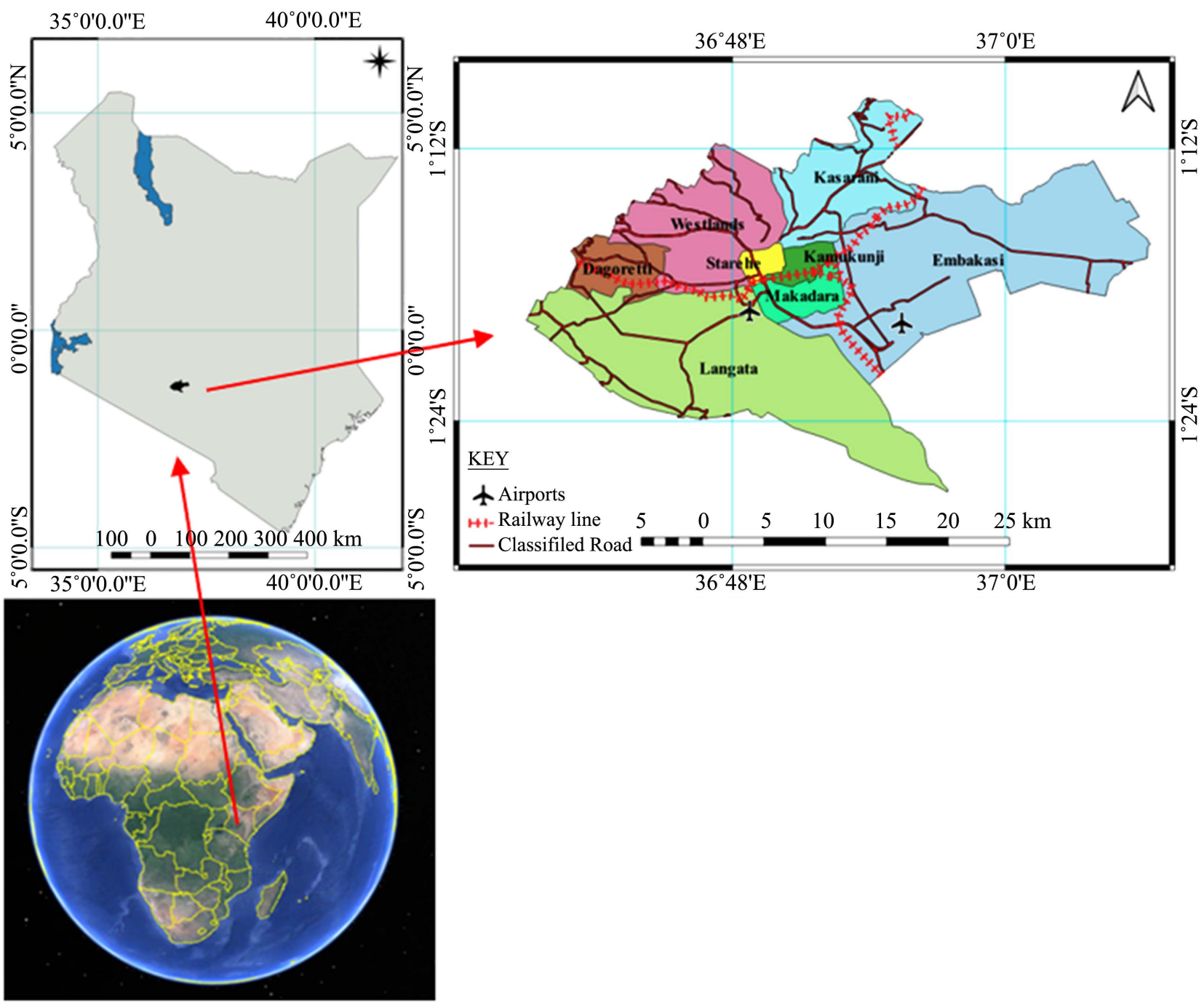

Figure 4. Nairobi city.

population) own a mobile phone [49]. The population in Nairobi has a higher per-capita income than the rest of the country, and for this reason mobile phone penetration is higher in Nairobi as compared to the rest of the country, this made Nairobi ideal for this study.

Nairobi had approximately $70 \%$ of its population accessible to mobile phone services in Figure 6 [49]. That implies that about 30\% of its population is not accessible to mobile phone services.

This also suggests that it is this population that is not qualified to this service and evidently being minors below 15 years of age, as shown in Figure 7 where the mean is greater than the median and is less than the mode. It depicts a deviation from normal distribution, with age ranging from 0 years to over 80 years of age with about $0.1 \%$ being 3571 not specifying their age. Table 1 with reverse cumulative frequency at $69.7 \%$ close to $70 \%$ indicate ages 15 and above, leaving $30 \%$ between ages 14 years to 0 years of age not possessing mobile phones, this age bracket lies between infancy to primary education level. 
Table 1. Female and male population of Nairobi by age.

\begin{tabular}{ccccc}
\hline Age Range & Male & Female & Total & Reverse Cumulative \% \\
\hline $0-4$ & 199,381 & 197,780 & 397,161 & $100.0 \%$ \\
$5-9$ & 151,900 & 154,977 & 306,877 & $87.3 \%$ \\
$10-14$ & 119,951 & 127,014 & 246,965 & $77.6 \%$ \\
$15-19$ & 115,772 & 154,292 & 270,064 & $69.7 \%$ \\
$20-24$ & 211,089 & 266,307 & 477,396 & $61.1 \%$ \\
$25-29$ & 234,596 & 228,157 & 462,753 & $45.9 \%$ \\
$30-34$ & 182,623 & 141,506 & 324,129 & $31.1 \%$ \\
$35-39$ & 134,459 & 95,173 & 229,632 & $20.8 \%$ \\
$40-44$ & 89,109 & 57,492 & 146,601 & $13.5 \%$ \\
$45-49$ & 65,901 & 41,102 & 107,003 & $8.8 \%$ \\
$50-54$ & 41,682 & 24,894 & 66,576 & $5.4 \%$ \\
$55-59$ & 24,304 & 14,981 & 39,285 & $3.3 \%$ \\
$60-64$ & 15,061 & 10,105 & 25,166 & $2.0 \%$ \\
$65-69$ & 7358 & 5664 & 13,022 & $1.2 \%$ \\
$70-74$ & 4462 & 4240 & 8702 & $0.8 \%$ \\
$75-79$ & 2424 & 2519 & 4943 & $0.5 \%$ \\
$80+$ & 3348 & 5175 & 8523 & $0.4 \%$ \\
Agg NS & 1810 & 1761 & 3571 & $0.1 \%$ \\
Total & $1,605,230$ & $1,533,139$ & $3,138,369$ & \\
\hline
\end{tabular}

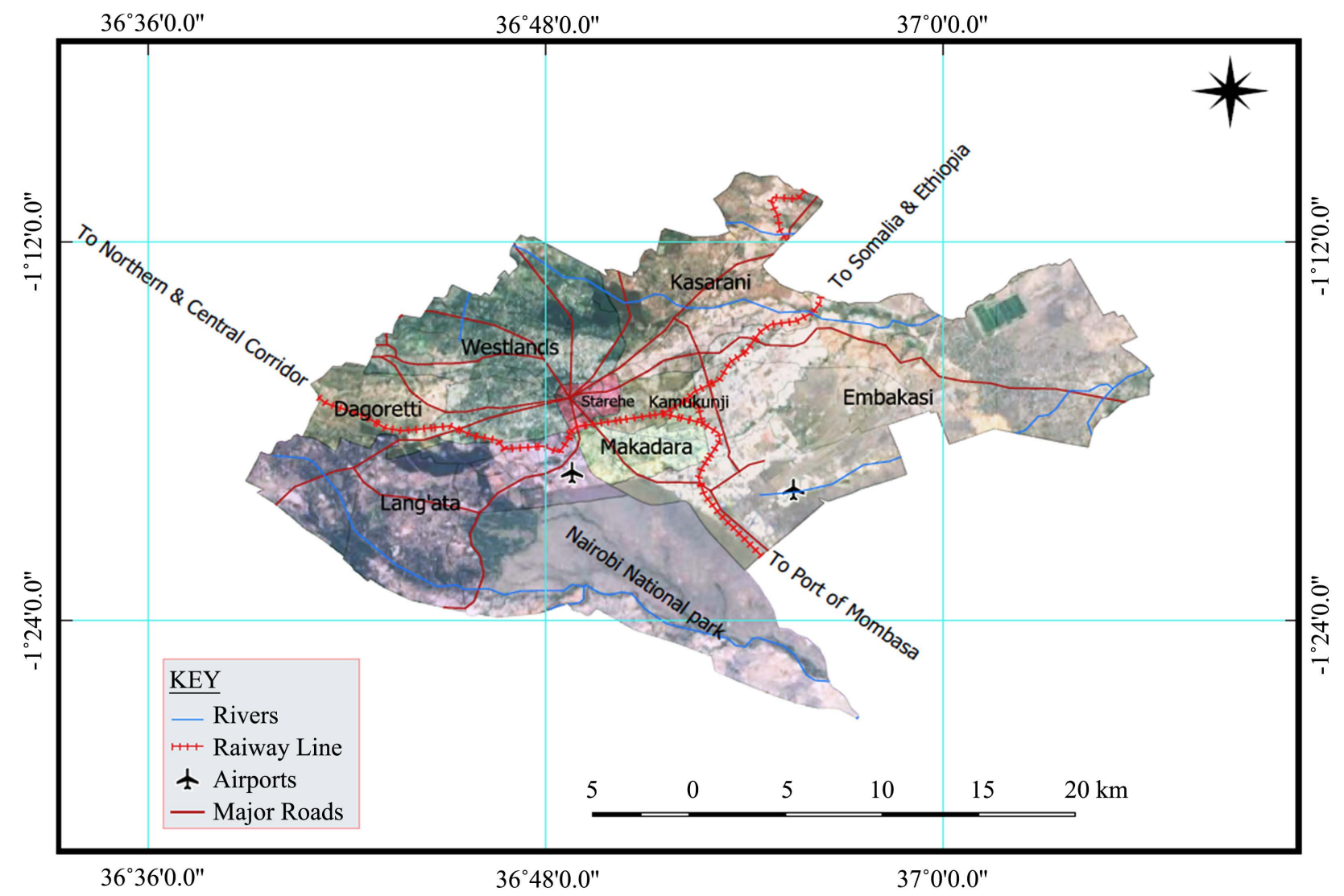

Figure 5. Nairobi hub for transport and trade. 


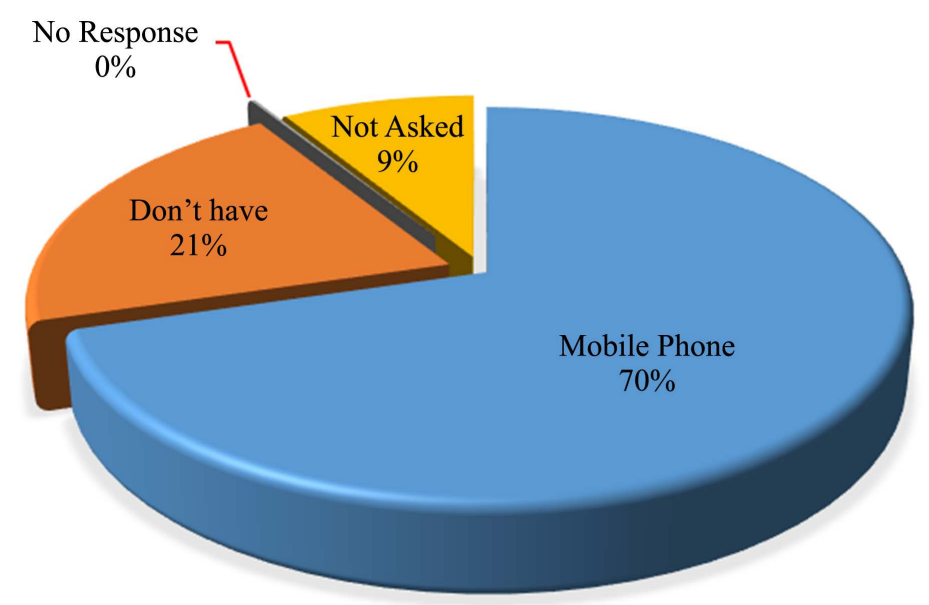

Figure 6. Population accessible to mobile phone service in Nairobi.

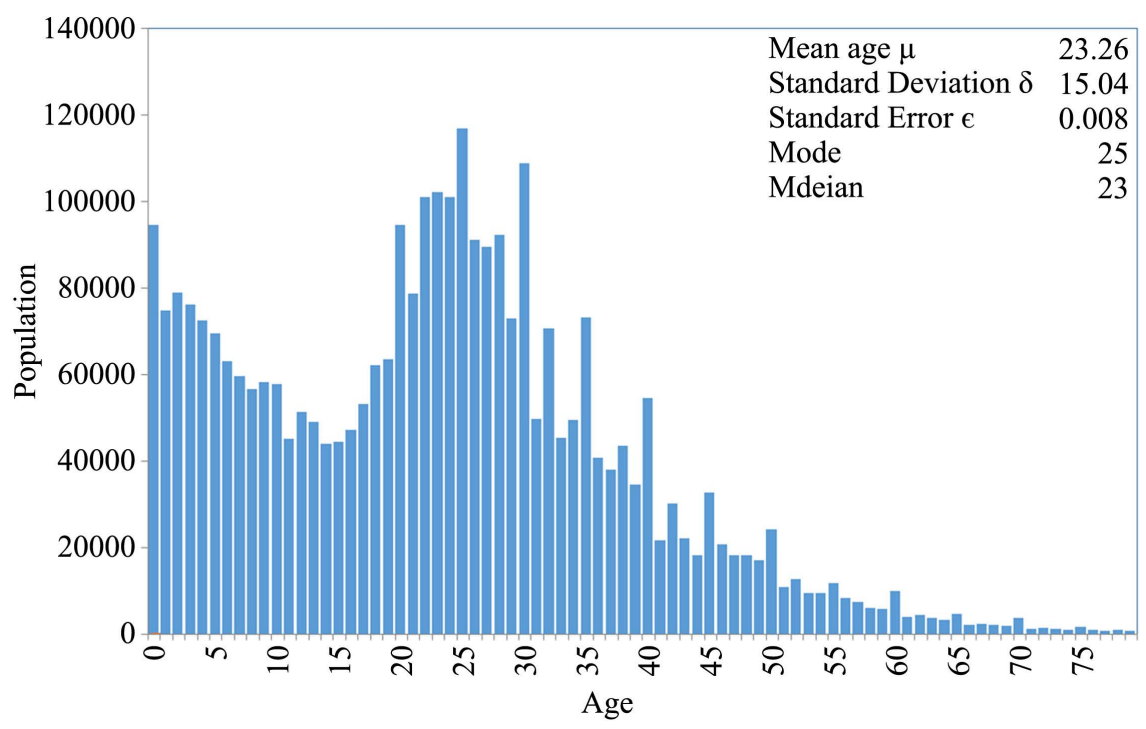

Figure 7. Population distribution of Nairobi by age.

Population distribution for Nairobi is provided by Figure 7 with a mean age of 23.26 years and standard deviation of 15.04 years. It is a bi-modal curve with two peaks at 0 year and 25 years which is as well as the mode for the population and a median at 23 years. The age ranges from less than 1 year to over 80 years of age and above with about $0.1 \%$ that being 3571 their age not specified.

\subsection{Technology Acceptance and Adoption}

The paper utilized Technology Acceptance Model (TAM) technique invented by Davis (1989) by relating TAM variable to the study variables to determine level of acceptance and adoption of this application [45]. This research endeavors to investigate on the state of LBS technology in Nairobi, Kenya through a quantitative study deploying simple random sampling method of by-passers in Nairobi central business district (CBD) for three working days, with a sample population of 300 persons utilizing a questionnaire as an instrument for survey. 


\subsection{Questionnaire}

A questionnaire survey was carried out to investigate users' acceptance and utilization of this technology based on mobile phone usage, awareness and exploitation of LBS. A simple questionnaire comprising four sections namely introduction, general section, technical section and person details. An introductory statement explaining the motive of the research work with assurance on confidentiality of the respondents' answers, a general section which had general questions on mobile phones, technical section involving knowledge on LBS and GPS systems and lastly with personal details section that inquired on age, level of education among others but excluding respondents' identity. Permits were obtained from National Commission for Science, Technology, and Innovation (NACOTSI) and Nairobi County Government. The first section introduced a respondent to understand the objective of the questionnaire, whereas the general section dealt with communication media where mobile phones were featured. The technical section dealt with technical aspect as Location Based Services (LBS), with the last dealing in personal details of respondents. The study engaged four survey research assistants, two males and two females for gender balance.

\subsection{Sample Size Determination}

The population focused were individuals who own mobile phones and utilizes it for various tasks. According to the Kenya National Census of 2009, Kenya with a population of about 38.6 million people had about 17.8 million mobile phone users which is approximately $46 \%$ of the entire population whereas Nairobi the capital city with a total population of 3.1 million people had 2.2 million people owning a mobile phone which is about $70 \%$ of the population, as indicated in Table 2 [49].

Nairobi being a city and a business, commercial, communication and administrative center has a population with financial capability to acquire and utilize the devices. The research interest is to reach as many mobile phone users as

Table 2. Population accessible to mobile services.

\begin{tabular}{|c|c|c|c|}
\hline Region & Total Population & Mobile Phone Users & $\%$ \\
\hline Kenya & $38,610,097$ & $17,968,269$ & $46.5 \%$ \\
\hline Nairobi & $3,138,369$ & $2,208,180$ & $70.4 \%$ \\
\hline Central & $4,383,743$ & $2,650,721$ & $60.5 \%$ \\
\hline Coast & $3,325,307$ & $1,512,680$ & $45.5 \%$ \\
\hline Eastern & $5,668,123$ & $2,583,759$ & $45.6 \%$ \\
\hline North Eastern & $2,310,757$ & 335,275 & $14.5 \%$ \\
\hline Nyanza & $5,442,711$ & $2,636,892$ & $48.4 \%$ \\
\hline Rift Valley & $10,006,805$ & $4,185,248$ & $41.8 \%$ \\
\hline Western & $4,334,282$ & $1,755,132$ & $40.5 \%$ \\
\hline
\end{tabular}


possible within a limited spatial extent for the evaluation of LBS technology, hence Nairobi CBD formed the most ideal locality for the study. Nairobi CBD comprising areas within Kencom House, Hilton Hotel, Achieves, and Ambassador Hotel were earmarked for questionnaire distribution. It forms a communication center and links to other parts of the city, which hosts many people on transit to various areas in the city in search of goods and services [51].

\subsection{Field Survey}

The research adopted a simple random sampling method of passers-by through Nairobi CBD using a simple, precise, and short questionnaire. Evaluation was carried out through a quantitative analysis using SPSS and Microsoft Excel. The sample size was determined by consideration of Nairobi County vastness and sample area chosen where it was easy and cheap to circulate the questionnaire and as per the permission granted from Nairobi County Administration. Nairobi CBD being a communication terminal and interchange for many commuters and businesspersons, a link to business premises, administrative functions, entertainment among other activities was the most ideal choice. The days chosen were working days from Tuesday to Thursday starting at 7 am to $6 \mathrm{pm}$. A simple random sampling method was adopted where any person walking through this area could be picked. The respondent filled the questionnaire and returned to the survey assistants in less than five minutes. The responses were fed in Microsoft Excel for loading in SPSS for analysis thereafter. The results of the analysis based on answers provided helped form a view on where key areas for interrogations on mobile phone applications were to be explored. Notable results obtained included user attachment to mobile device, rating on ways of communication, awareness to positioning capability in mobile phones, inquest on travel and information seeking habits.

\subsection{Technology Acceptance and Adoption}

Using Technology Acceptance Model, the research implemented a direct relationship between TAM variables and questionnaire variables to determine on acceptance and adoption of LBS technology based on questionnaire survey outcome as outlined in Figure 8. Based on six main segments of TAM, External Variable $(\mathrm{EV})$ was linked with preference to mobile phone as a media to communication and information dissemination being an external cause of LBS by the fact of hosting it. Perceived Use (PU) was related to GPS awareness having knowledge of GPS technology and being able to clearly identify whether it exists on one's mobile phone or not. Perceived Ease of Use (PEOU) was associated with mobile phone enslavement being the time one is attached or hangs with mobile phone and also dependent on one's education attainment level with consideration of college education and higher levels presuming these levels to have at least some working knowledge on LBS and GPS. Attitude (A) was linked to social activity of users as they always/often/sometimes move or travel from one location to another. Behaviour Intention (BI) related to enquiries by user as they 


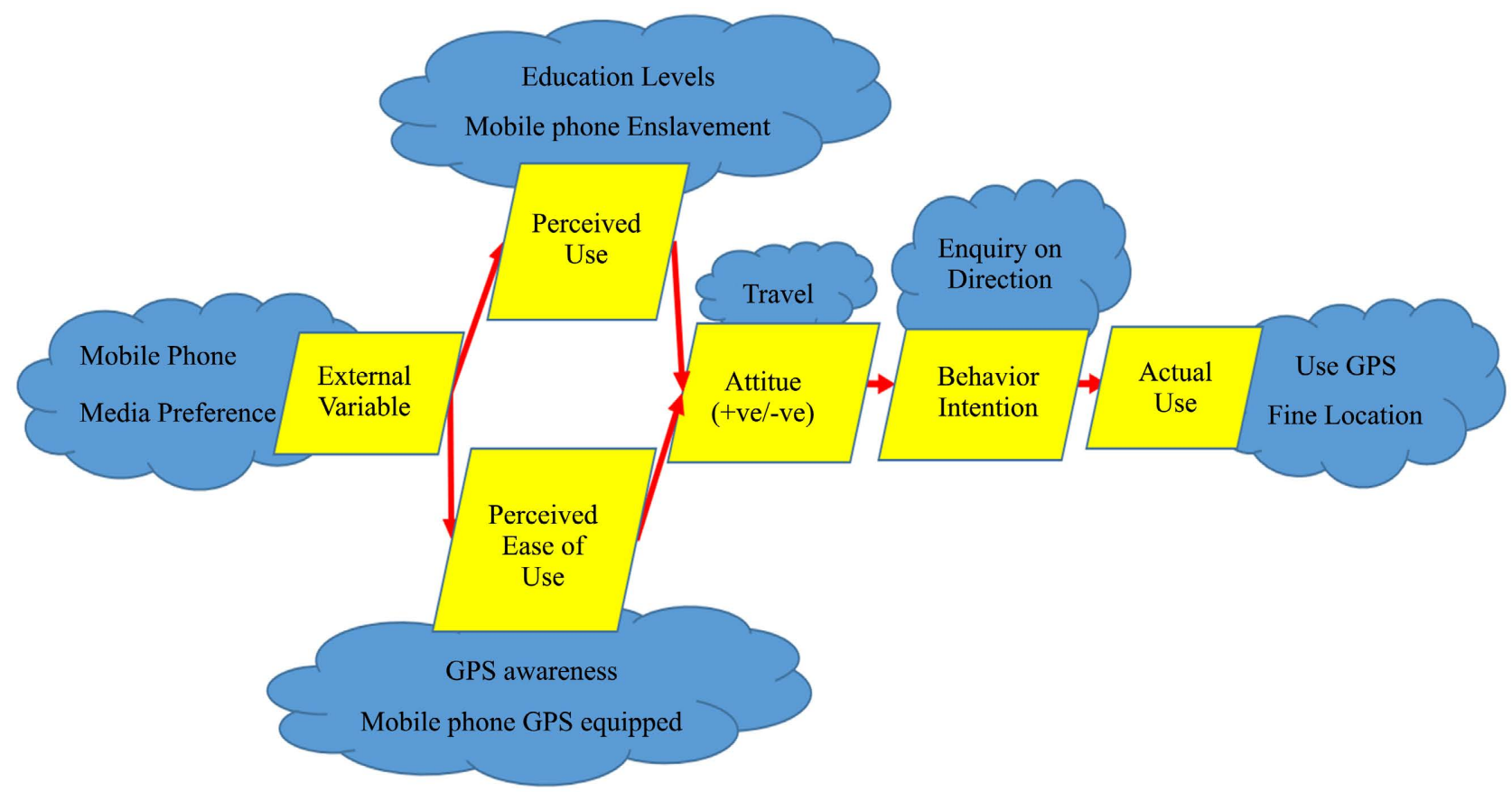

Figure 8. Relationship between TAM variables and questionnaire variables.

always/often/sometimes find direction as they move to new locations, with Actual Use (AU) being associated to always find location using one's mobile phone and always Use of GPS functionality on mobile phone.

\section{Results}

\subsection{Quantitative Analysis of Mobile Phone Users}

Out of 300 questionnaires issued, 276 responses were obtained this was $92 \%$ return rate, of which 204 were male and 57 were female with 15 not stating their gender. This shows bias as a huge difference exists in gender response based on unwillingness to respond to the survey emerging mostly from female participants. The Mean age of respondents was about 27 years with a standard deviation of 7.8 years, age ranging between 15 to 54 years, with mode at 24 years and median at 25 years. The number of respondents starts dwindling as from age 28 years onwards terminating at 54 years as shown in Figure 9.

The respondents came from as far as Rwanda and Uganda, which are neighbouring countries to Kenya as indicated in Table 3, about $0.8 \%$ while 254 respondents $92 \%$, the bulk reside in various part of the country.

Respondents from Kenya were distributed in various parts of the country including Central Kenya, Western Kenya, Nyanza region, part of the Rift Valley, Eastern and Coastal region, with a majority from the study area, Nairobi County as portrayed in Table 4 and visualized in the distribution map of respondents' area of residence in.

Respondents who reside in Nairobi were $46 \%$ of the total from Kenya whereas those from other counties were $54 \%$ as illustrated in Figure 10. The counties 
Table 3. Respondents' country of residence.

\begin{tabular}{ccc}
\hline Country & No. of Respondents & Percentage \\
\hline Kenya & 254 & $92.0 \%$ \\
Uganda & 1 & $0.4 \%$ \\
Rwanda & 1 & $0.4 \%$ \\
No Response & 20 & $7.2 \%$ \\
& 276 & $100.0 \%$ \\
\hline
\end{tabular}

Table 4. Respondents' county of residence.

\begin{tabular}{|c|c|c|c|}
\hline County & No. of Respondents & Percentage & Cumulative Percentage \\
\hline Baringo & 4 & $1.6 \%$ & $1.6 \%$ \\
\hline Bomet & 3 & $1.2 \%$ & $2.8 \%$ \\
\hline Bungoma & 7 & $2.8 \%$ & $5.5 \%$ \\
\hline Busia & 3 & $1.2 \%$ & $6.7 \%$ \\
\hline Elgeyo Marakwet & 2 & $0.8 \%$ & $7.5 \%$ \\
\hline Embu & 2 & $0.8 \%$ & $8.3 \%$ \\
\hline Homa Bay & 6 & $2.4 \%$ & $10.6 \%$ \\
\hline Kajiado & 7 & $2.8 \%$ & $13.4 \%$ \\
\hline Kakamega & 5 & $2.0 \%$ & $15.4 \%$ \\
\hline Kericho & 3 & $1.2 \%$ & $16.5 \%$ \\
\hline Kiambu & 28 & $11.0 \%$ & $27.6 \%$ \\
\hline Kilifi & 1 & $0.4 \%$ & $28.0 \%$ \\
\hline Kirinyaga & 2 & $0.8 \%$ & $28.7 \%$ \\
\hline Kisii & 3 & $1.2 \%$ & $29.9 \%$ \\
\hline Kisumu & 4 & $1.6 \%$ & $31.5 \%$ \\
\hline Kitui & 2 & $0.8 \%$ & $32.3 \%$ \\
\hline Laikipia & 1 & $0.4 \%$ & $32.7 \%$ \\
\hline Machakos & 12 & $4.7 \%$ & $37.4 \%$ \\
\hline Makueni & 3 & $1.2 \%$ & $38.6 \%$ \\
\hline Meru & 2 & $0.8 \%$ & $39.4 \%$ \\
\hline Migori & 3 & $1.2 \%$ & $40.6 \%$ \\
\hline Mombasa & 1 & $0.4 \%$ & $40.9 \%$ \\
\hline Murang'a & 4 & $1.6 \%$ & $42.5 \%$ \\
\hline Nairobi & 118 & $46.5 \%$ & $89.0 \%$ \\
\hline Nakuru & 4 & $1.6 \%$ & $90.6 \%$ \\
\hline Nandi & 4 & $1.6 \%$ & $92.1 \%$ \\
\hline Narok & 1 & $0.4 \%$ & $92.5 \%$ \\
\hline Nyeri & 7 & $2.8 \%$ & $95.3 \%$ \\
\hline Siaya & 6 & $2.4 \%$ & $97.6 \%$ \\
\hline Taita Taveta & 1 & $0.4 \%$ & $98.0 \%$ \\
\hline Trans-Nzoia & 1 & $0.4 \%$ & $98.4 \%$ \\
\hline Uasin Gishu & 4 & $1.6 \%$ & $100.0 \%$ \\
\hline
\end{tabular}




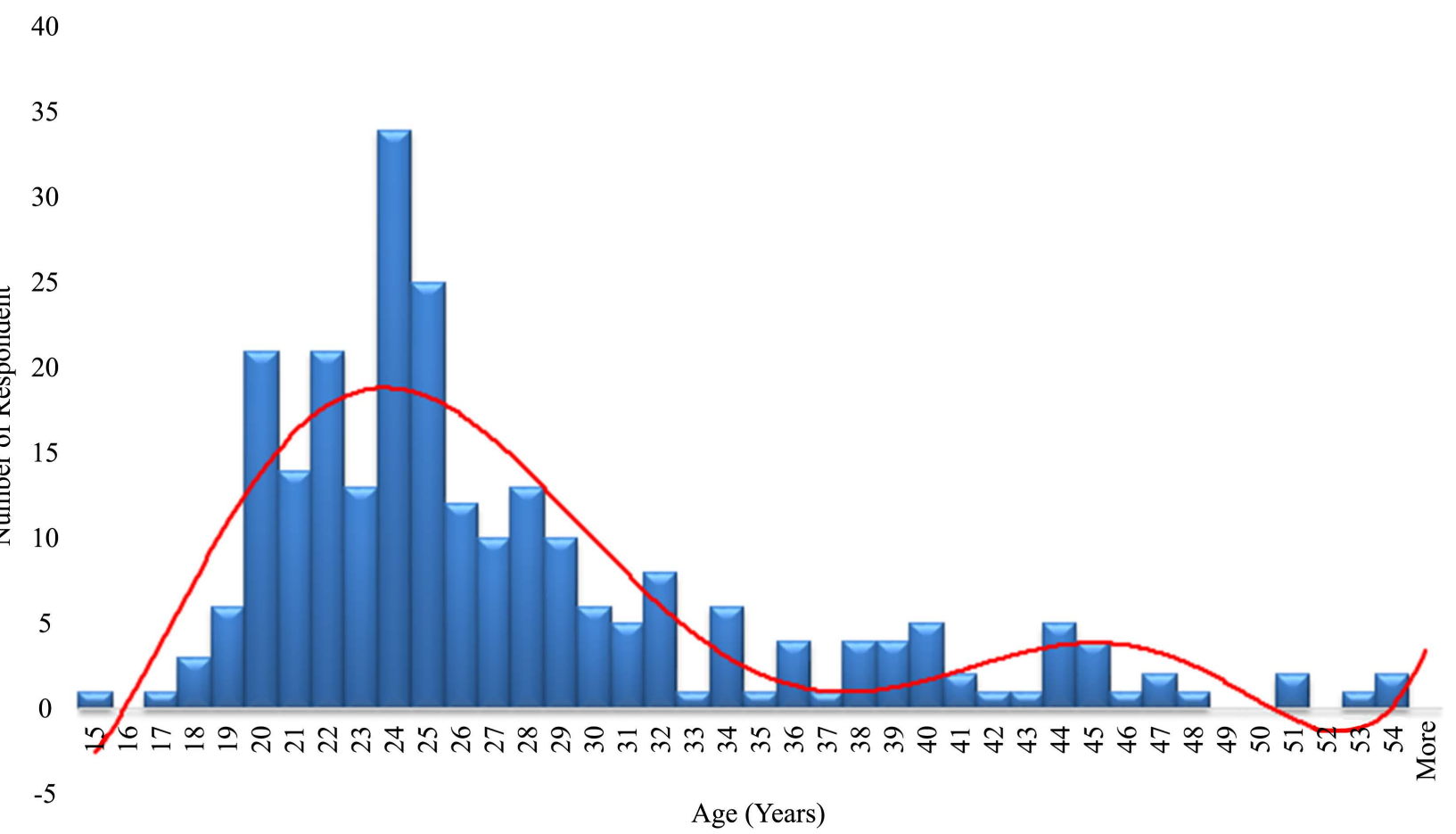

Figure 9. Questionnaire respondents by age.

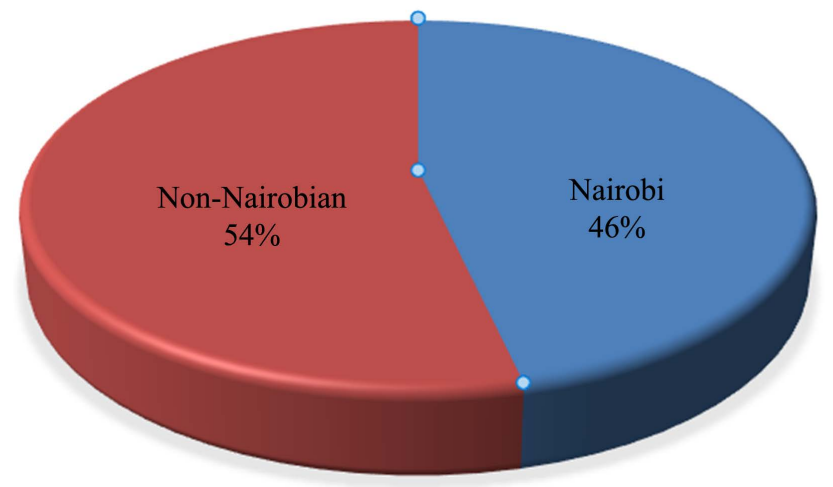

Figure 10. Respondents residential address.

close to Nairobi had a large contribution to the number of respondents than those farther away as shown in the map in Figure 11.

Based on gender, Figure 12 indicates low participation from female respondents at $21 \%$ compared to male counterpart at $74 \%$ while $5 \%$ did not respond.

Dealing with respondents of both female and male sex, the survey engaged a gender balanced composition of research survey assistants of two female and two male to avoid any biases towards a particular gender. Figure 13 shows proportion by which each survey assistant interacted with participants, MM (Female) covered $16 \%$ of the interactions, after losing out $26 \mathrm{No}$. of responses to a pick-pocket who snatched her handbag which contained questionnaire responses. NM (Female) covered 25\% whereas JM (Male) covered 30\% with KEM (Male) covering $29 \%$. 


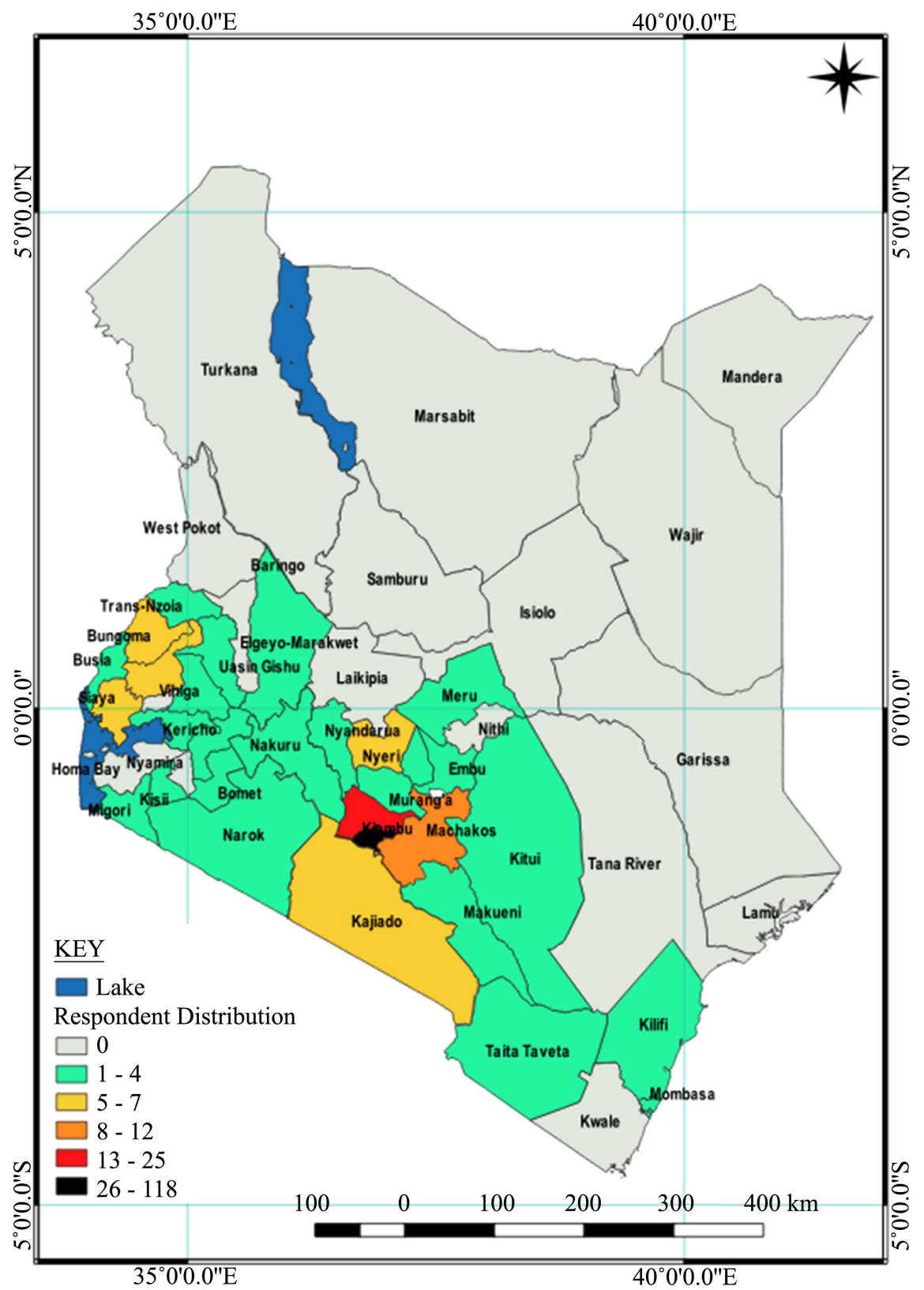

Figure 11. Respondents' area of residence.

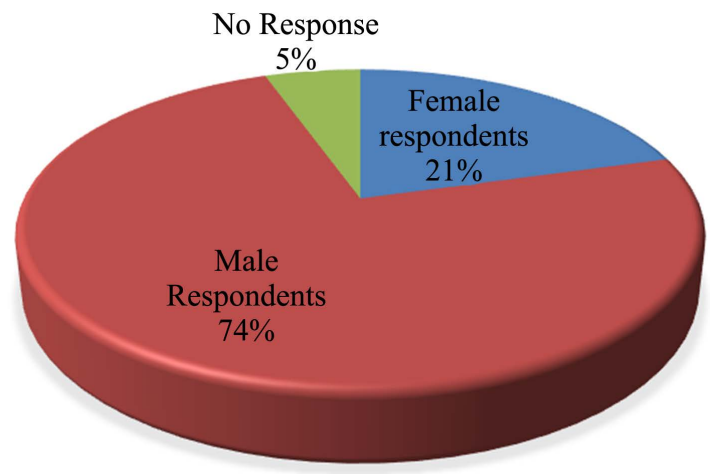

Figure 12. Respondents by gender. 


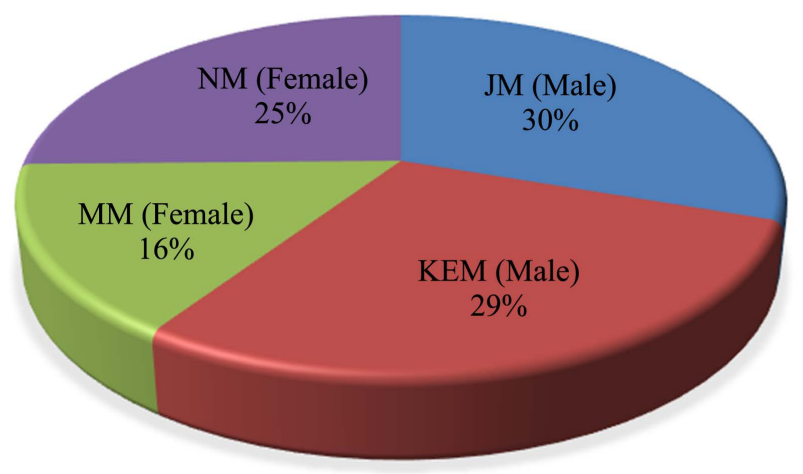

Figure 13. Survey assistants interaction with respondents.

Figure 14 shows interaction of each survey assistant with different gender. It shows proportion of each gender interaction with the research survey assistants, proportionate to their coverage. The interaction for each research survey assistants outreach ratio for female to male at worst 1:6 and 2:5 at best.

Education consideration is highlighted in Figure 15 which shows a big majority of respondents as well educated with over $88 \%$ that is 213 respondents having attained secondary education and above. Education level by gender was also proportionate with female being few but similar in variation at different education levels. Majority of respondents 102 in number being $40 \%$ had attained University Education to Postgraduate. Those who had no formal education were just one respondent only and eight respondents at $3 \%$ had primary education. Those who did not respond were 14 respondents at $4 \%$.

In Figure 16 there is a strong correlation of education background for both female and male respondents, as it uniformly varies at different stages of education levels distributed proportionately.

User relationship with mobile phones in terms of time of possession of these devices or by which a user is in contact. It can be illustrated in Figure 15 that $68 \%$ that is 187 respondents have their mobile phone for over 12 hours, with about $18 \%$ that is 50 respondents have it from 8 hours to 12 hours, $7 \%$ being 18 respondents handle it as from 4 hours to 8 hours, $4 \%$ that being 12 respondents within 1 hour to 4 hours, $1 \%$ that is 3 respondents under 1 hour while $2 \%$ that is 6 respondents did not respond on this question, this is shown in Figure 17.

Mobile phone was picked out as the most favorite form of media for information transmission and dissemination at $89.2 \%$ rating as most used, followed a distance second by Computer \& Internet at $55.9 \%$ rating, Television at $53.7 \%$ and Radio at $46.4 \%$ as shown in Figure 18, with the worst being letters with a rating of $2 \%$ as most used median. Newspaper and Landline Telephone have $22.7 \%$ and $22.5 \%$ respectively.

\subsection{Personal Habits}

Inquest on mobile phone personal habit was made where respondents' travel, inquire on direction and time of day, are as shown in Figure 19. It can be seen 


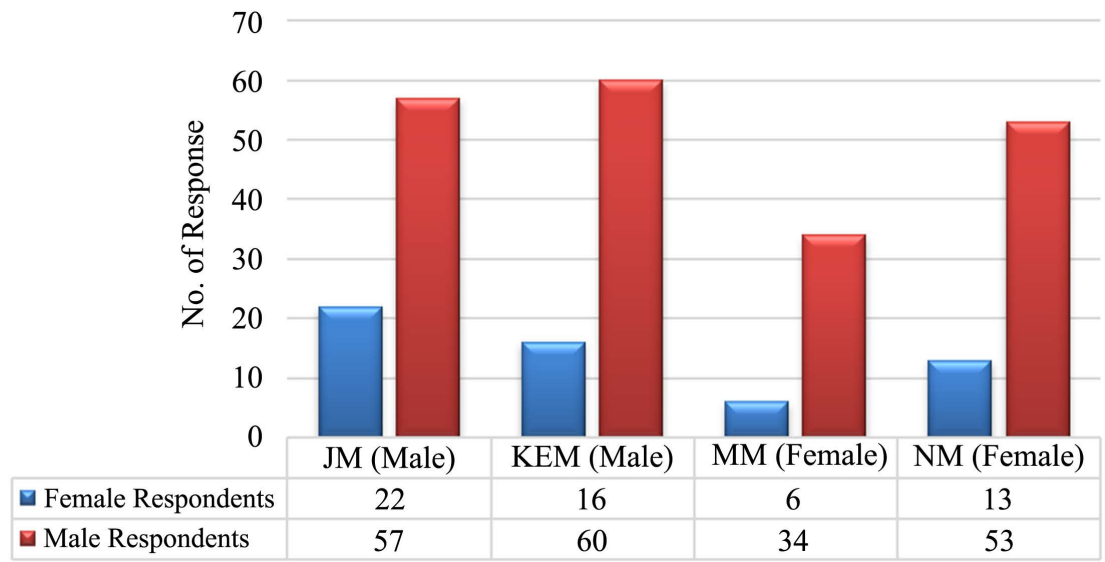

Figure 14. Survey assistants, interaction with respondents.

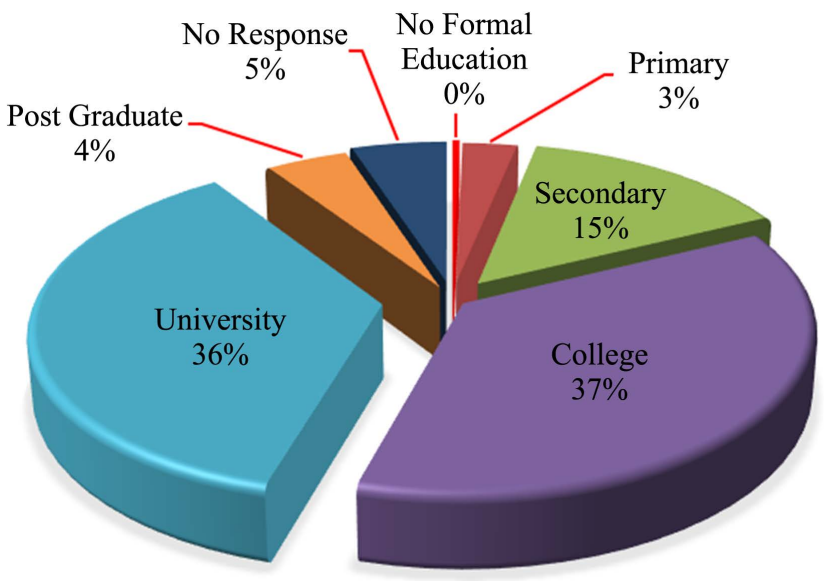

Figure 15. Respondents education levels.

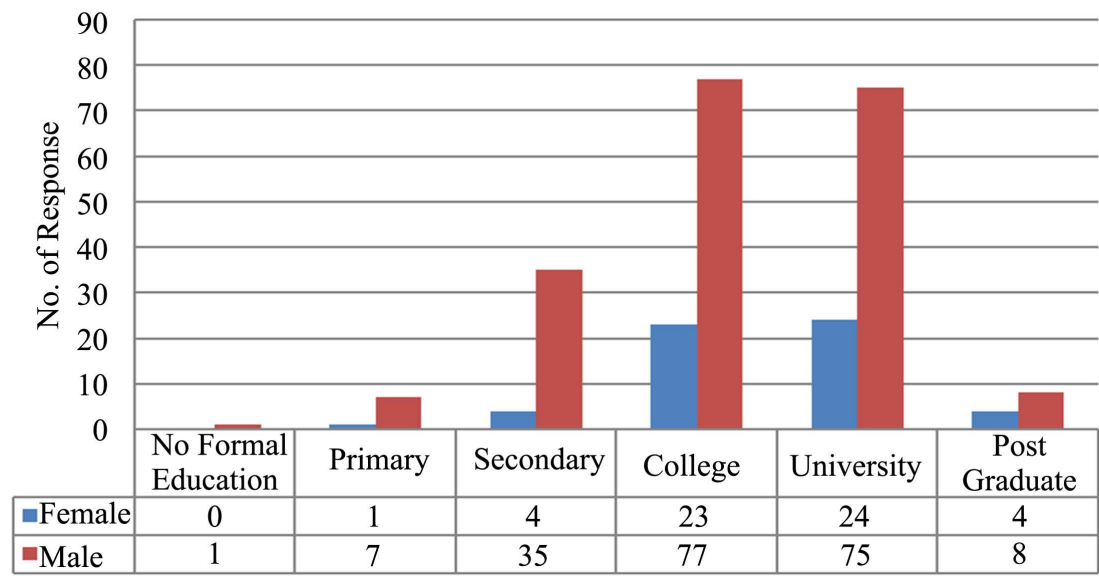

Figure 16. Education level by gender.

that 104 respondents always travel, 80 respondents often travel while 60 respondents sometimes travel as compared to 18 and 2 respondents who rarely and never travel respectively, with 12 respondents not answering back to the question on travel habits. 


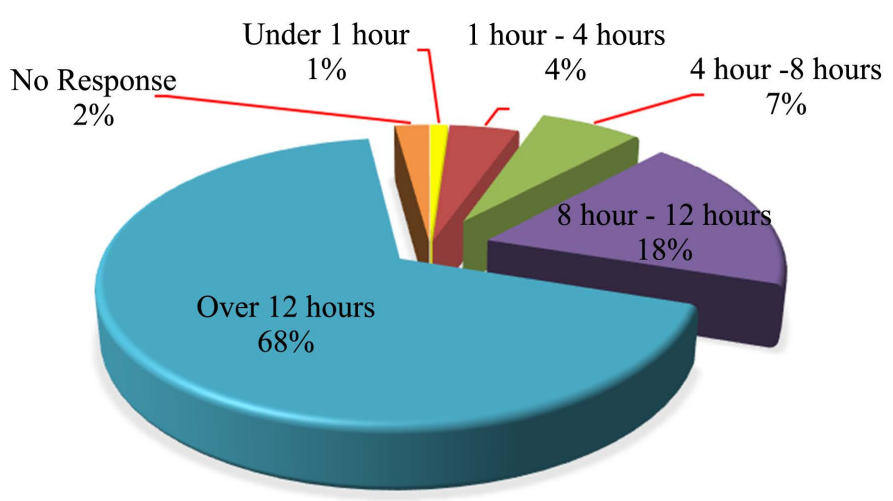

Figure 17. User/mobile phone time possession.

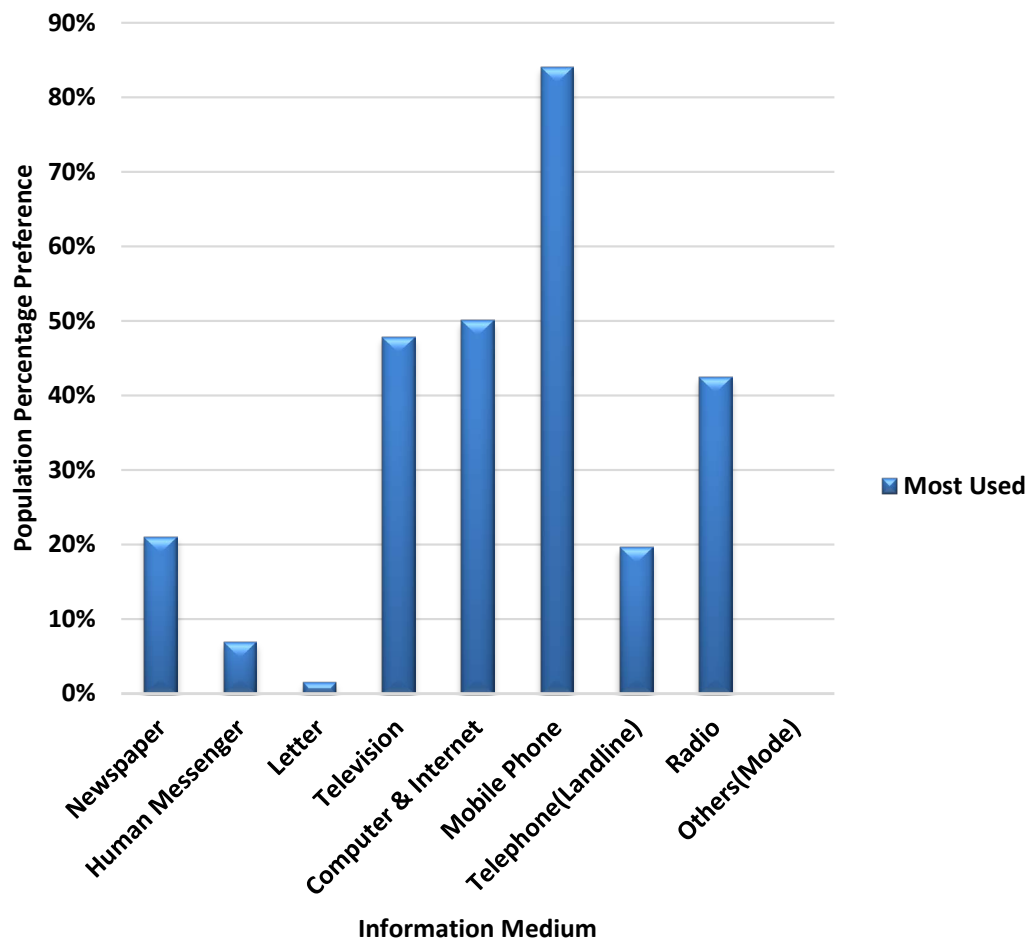

Figure 18. Information transmission preference.

Correspondingly Figure 20 shows $38 \%$ of the respondents always travel, $29 \%$ often, $22 \%$ sometimes travel while $6 \%$ rarely and $1 \%$ never travel, with about $4 \%$ not responding to the question on travel. This implies $89 \%$ at least always/often/sometimes travel.

On inquiry for direction, 20 respondents always enquire, while 35 respondents often enquire and 107 respondents sometimes enquire on direction issues, whereas 72 and 17 respondents rarely and never enquire on direction respectively with 25 respondents not answering to the question as indicated in Figure 19. Similarly, Figure 21 demonstrates that $7 \%$ inquire on direction, $13 \%$ often and $39 \%$ sometimes inquire on direction while $26 \%$ rarely and $6 \%$ never inquire on direction with $9 \%$ not responding to the question on direction inquiry. Therefore $59 \%$ always/often/sometimes inquire on direction. 
120

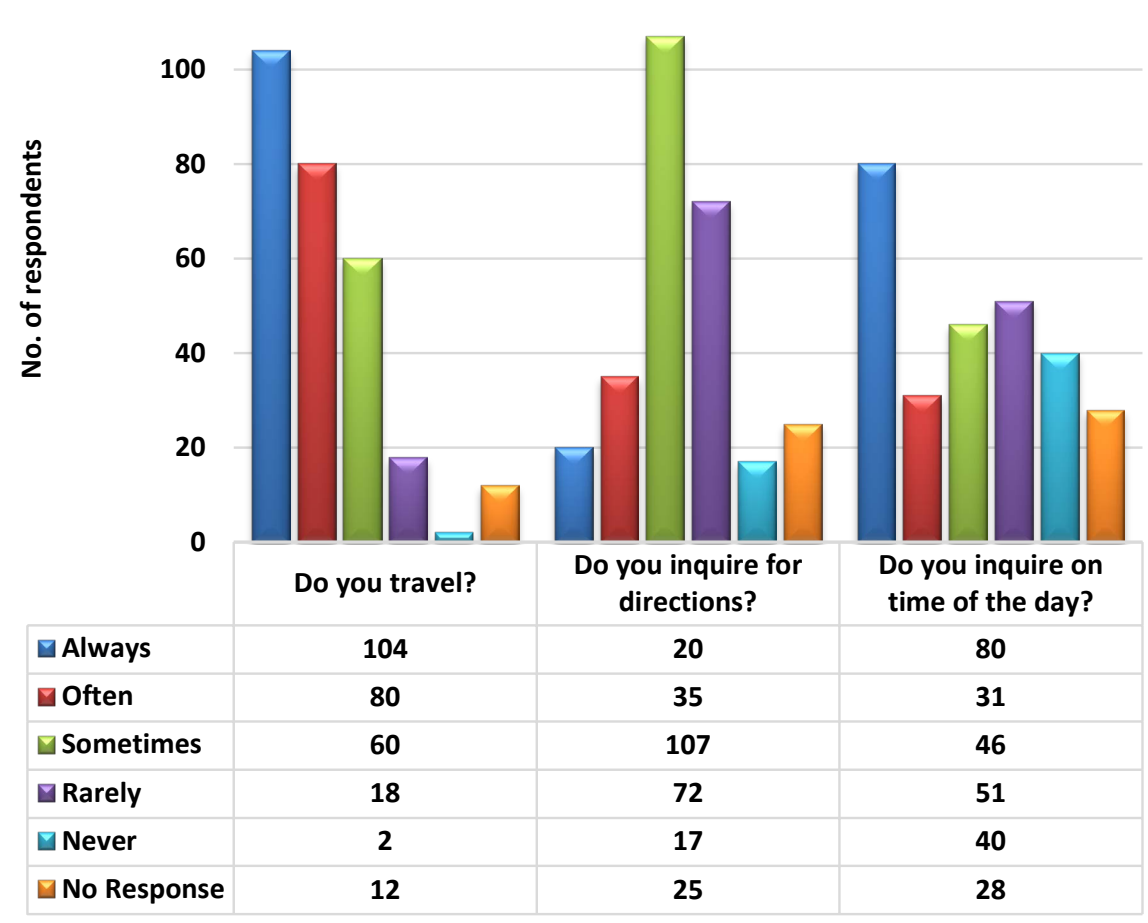

Figure 19. Personal habits.

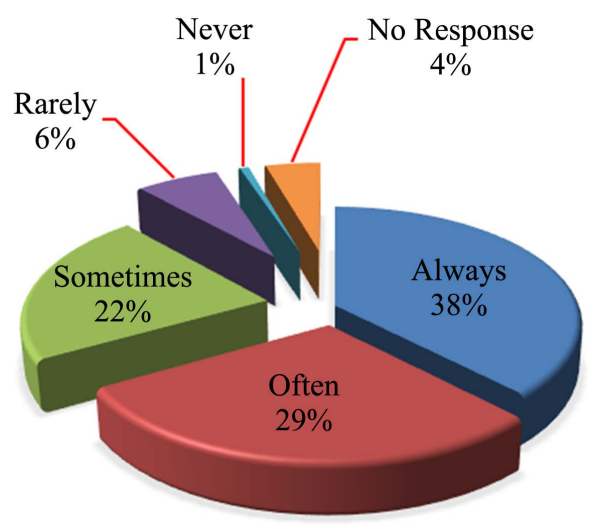

Figure 20. Those who travel.

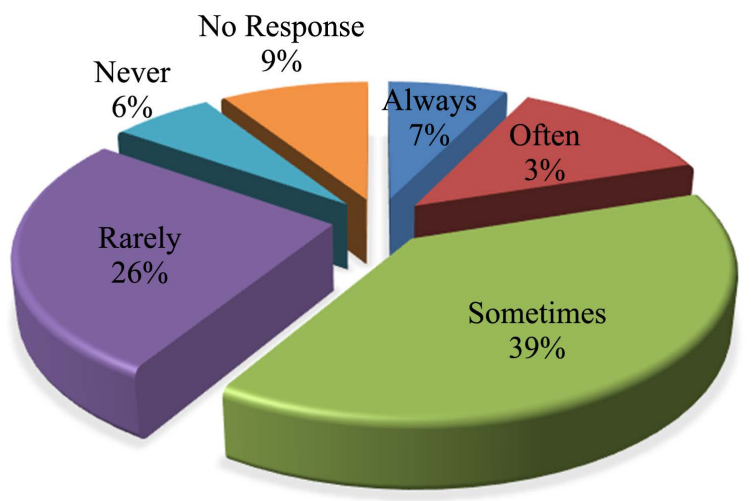

Figure 21. Inquire on direction. 
On issues on time, 80 respondents always enquire on time of day, while 31 respondents sometimes enquire and 46 respondents sometimes inquire on time, whereas 51 and 40 respondents rarely and never enquire on time respectively with 28 respondents not answering to the question as shown in Figure 19. Evidently Figure 22 shows that $29 \%$ always inquire on time of day, $11 \%$ often and $17 \%$ sometimes inquire on time of day whereas $18 \%$ rarely and $15 \%$ never ask on time of day thus $57 \%$ always/often/sometimes inquire on time of the day.

In terms of cost of mobile phones, Figure 23 shows that about 210 respondents had mobile phones that cost less than Ksh 10,000/= that was approximately $78 \%$, while about 76 respondents about $22 \%$ had mobile phones that cost over Ksh. $10,000 /=$.

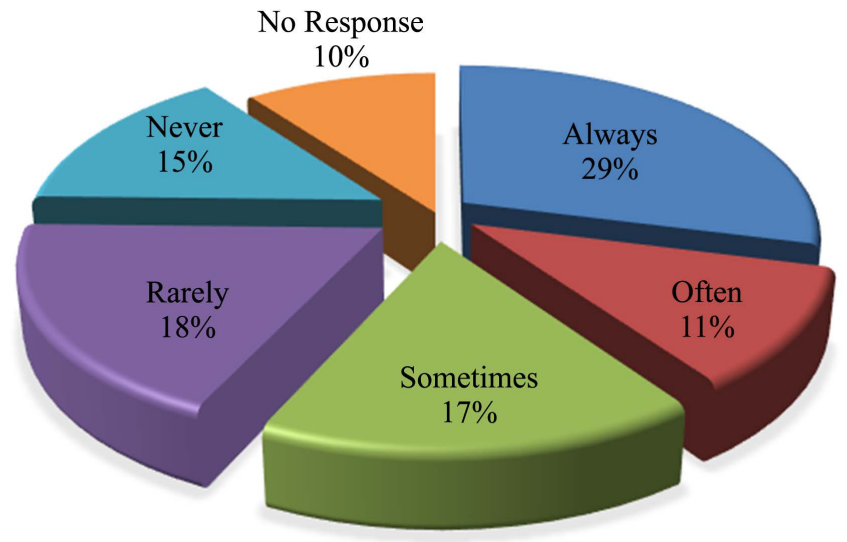

Figure 22. Time of day inquiry.

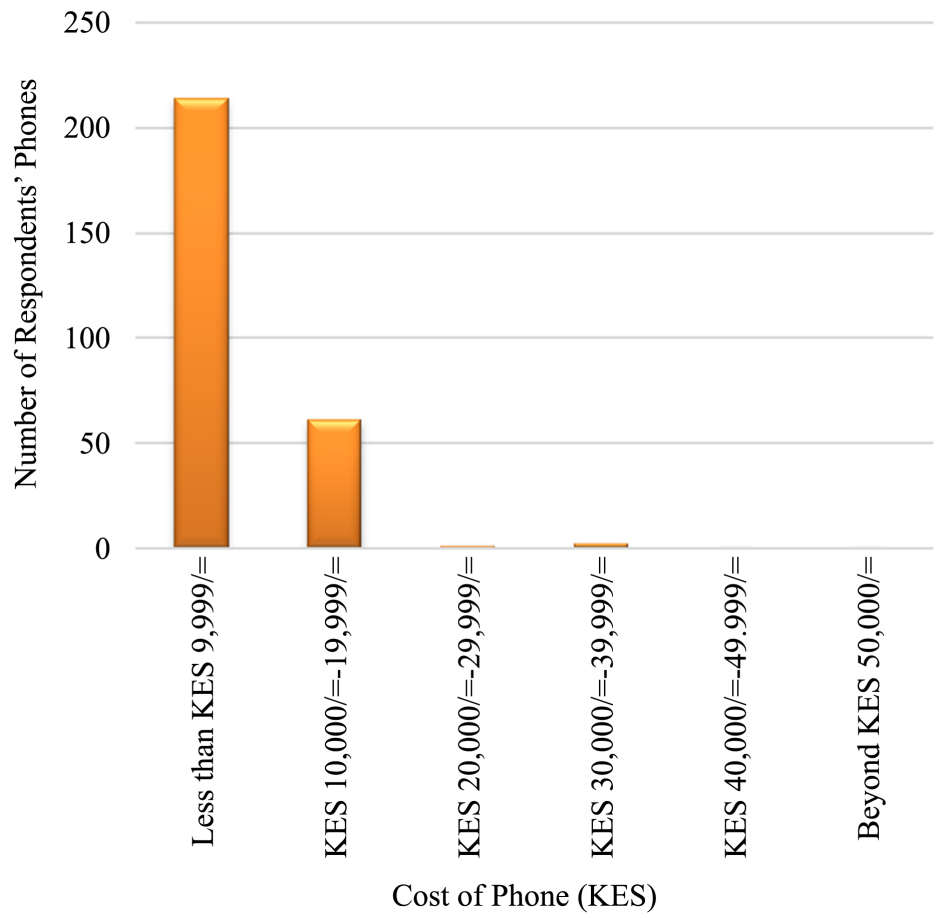

Figure 23. Mobile phone cost. 
Mobile phones come in different makes from various manufacturers, with different features on board. These form preference for choice that user make when purchasing mobile phones, this is indicated in Figure 24. On a Likert scale rating from extremely important to not important. Among the factors outlined is price which indicates $37.3 \%$ representing 103 respondents prefer price as extremely important factor, $58 \%$ that is 160 respondents prefer functions on mobile phone. Smartphone and brand are considered at $26.8 \%$ being 74 respondents and $24.6 \%$ being 68 respondents respectively. Touch screen at $15.2 \%$ representing 42 respondents with the least in consideration being small screen size preference at $5.1 \%$ being 14 respondents.

\subsection{LBS Awareness and Usage}

Mobile phone is a hardware that hosts various applications, which assist users with a variety of tasks in real life. Among the applications are given in Figure 25, where internet access, clock and SMS service are rated over $60 \%$ as always used application followed by voice call, money transfer and alarm at $45.3 \%, 42.4 \%$ and $34.8 \%$ respectively. The least in choice is TV viewing on mobile phone at $6.5 \%$. Find location is a navigational application which belongs in the LBS family, was rated at $10.1 \%$ as always used. Other applications on always used rating included calendar at $34.4 \%$, picture and video at $26.8 \%$, social media at $12 \%$.

From the pie chart in Figure 26, it reveals that $72 \%$ that is 198 respondents were aware of GPS functionality on their mobile phone, with $13 \%$ representing 35 respondents not aware about it at all. It is also evident that $5 \%$ being 15 respondents were not sure, $6 \%$ that is 17 respondents had no idea about GPS with $4 \%$ that is 11 respondents not responding.

From Figure 27 illustrate use of GPS functionality on mobile phone where $22 \%$ representing 61 respondents always/often/sometimes use GPS functionality on their mobile phones while $8 \%$ which is 21 respondents rarely and never use

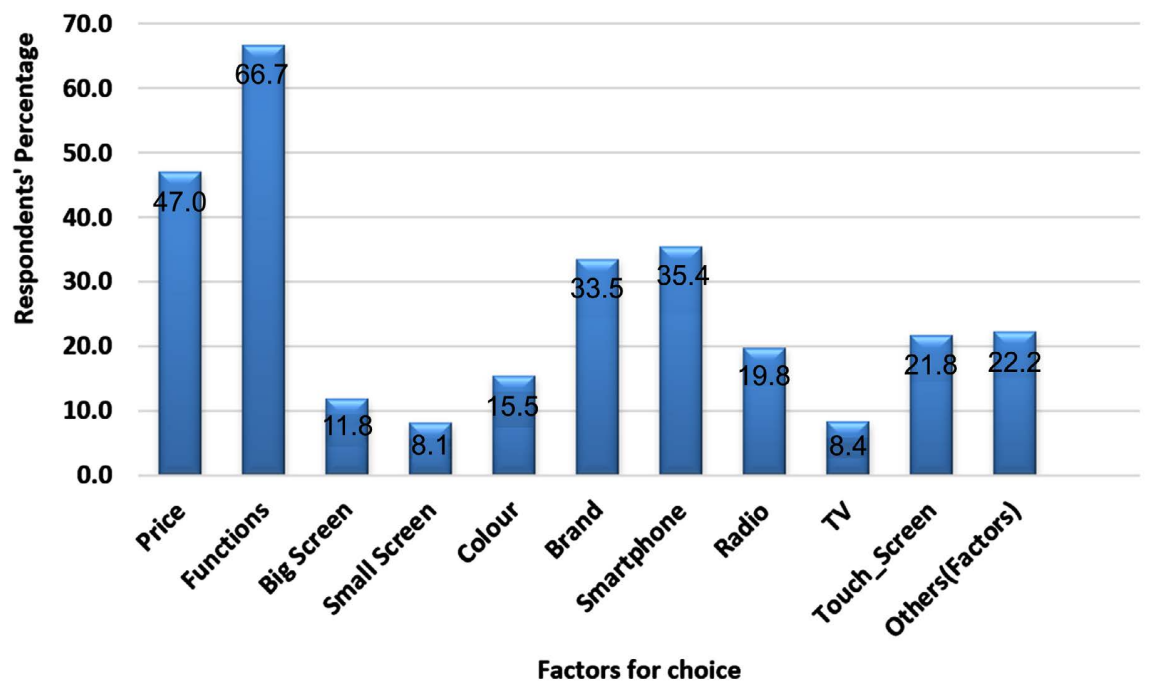

Figure 24. Mobile phone purchase factors considerations. 


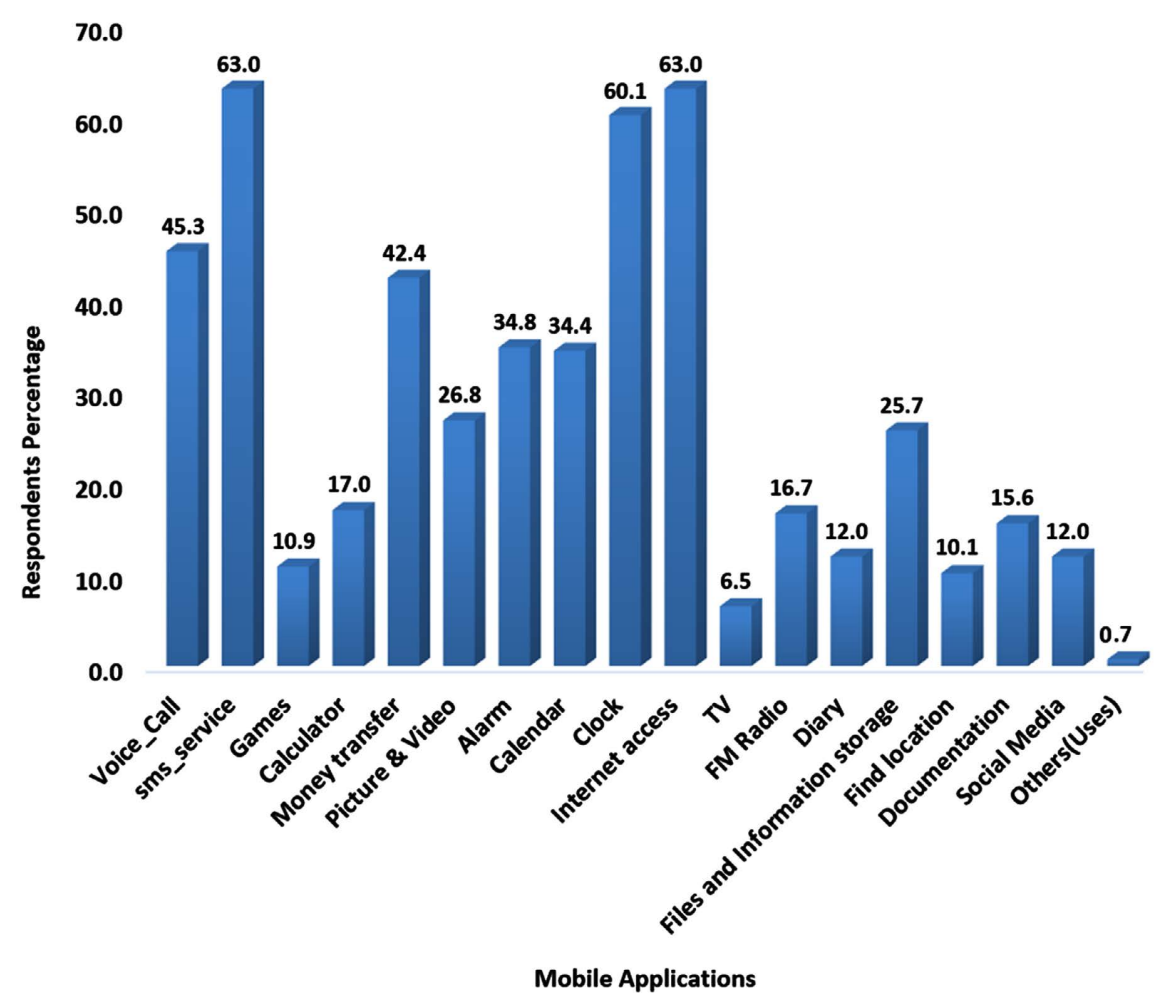

Figure 25. Chart on always used mobile phone applications.

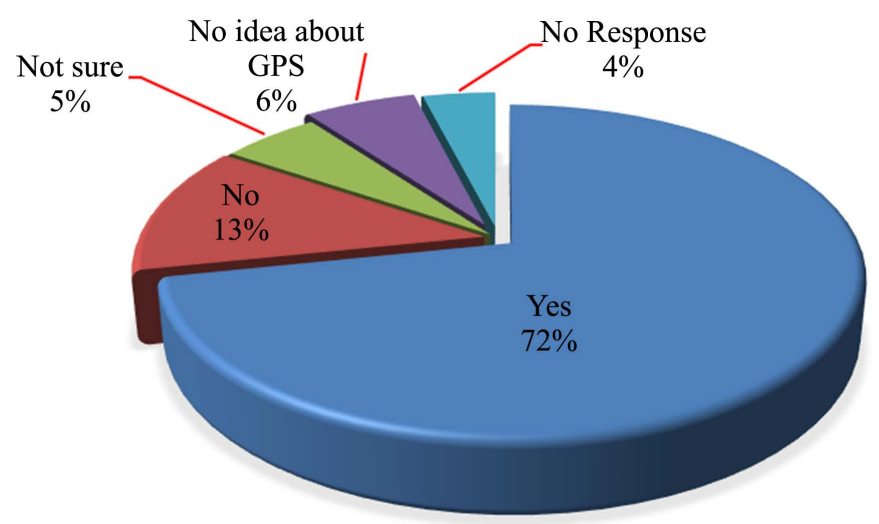

Figure 26. GPS awareness.

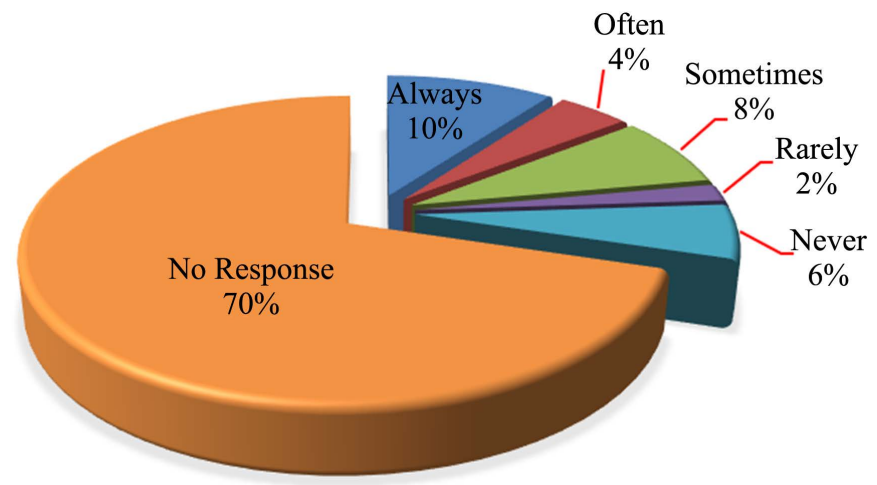

Figure 27. Use GPS functionality on their mobile phone. 
this functionality. A big number of about 70\% representing 198 respondents did not react to this question on use of GPS functionality on mobile phone.

The response on whether one minds being located by the fact that mobile phone position is determined with GPS attachment hence the user location known. These split respondents almost in the middle with those for being $35 \%$ signifying 92 respondents while against on revelation of their location at 32\% signifying 84 respondents. Only 1 respondent $1 \%$ felt it is not important with about $32 \%$ being 84 respondents not reacting to the question on locating user position by mobile phone as shown in Figure 28.

For gender parity, it is apparent that more females did not mind their location being known with 17 respondents for while 15 respondents against as revealed from Figure 29. For male a higher number 77 respondents minds on their location being determined while 67 respondents would not mind. The number

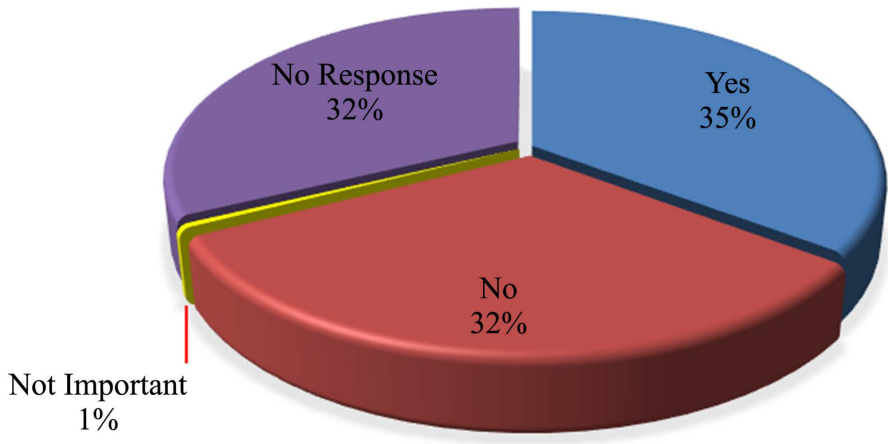

Figure 28, Mind your location determination.

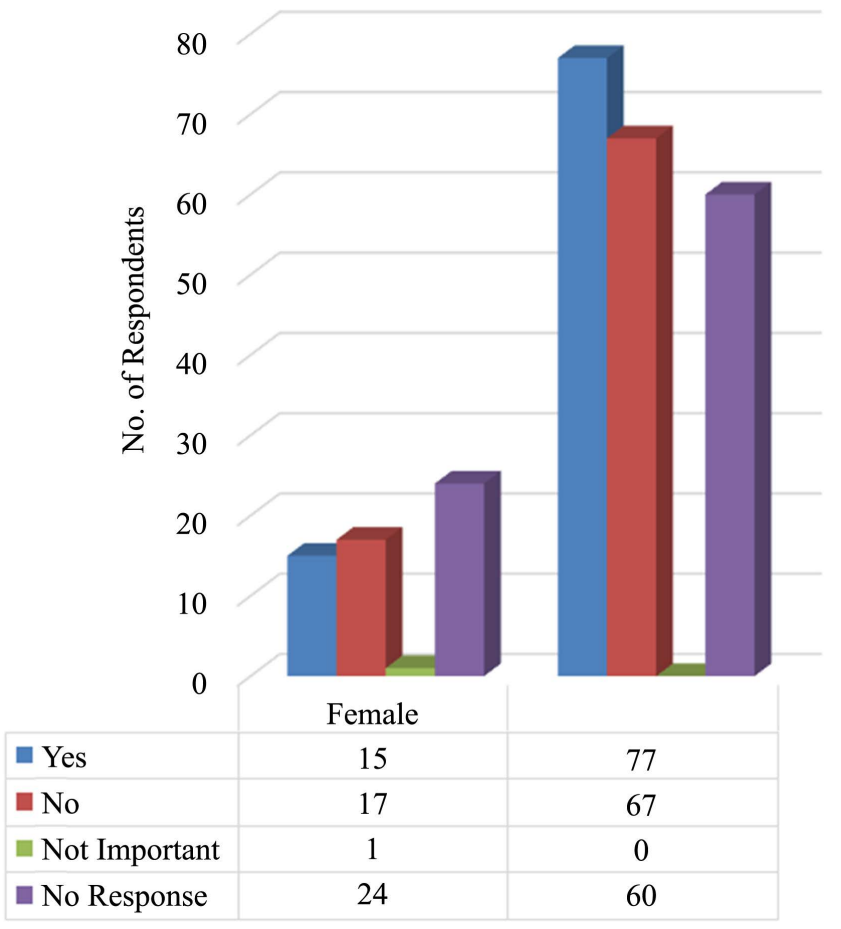

Figure 29. Mind your location by gender. 
of respondents who did not react to this is very high for female at 24 respondents higher than the yes and no, while for male was at 60 respondents just slightly below the yes and no proponents. It was almost balance in equal proportion with both genders splitting almost in the middle for and against as demonstrated in Figure 29.

\subsection{Technology Acceptance Model (TAM)}

The percentage scored from questionnaire response were used to analyze where the mean was determined with the consideration of all six segments referred from Figure 8. These were External Variable (EV), Perceived Ease of Use (PEOU), Perceived Use (PU), Attitude (A). Behaviour Intention (BI) and Actual Use (AU) were mapped to the research variables scores as indicated in Table 5. With a sample size $(n)$ of 9 , the mean $(\mu)$ was $0.628 \%$ at $95 \%$ confidence level, using a T-distribution left hand tailed curve as the sample size is less than 30 .

Table 5. Technology acceptance model for LBS.

\begin{tabular}{|c|c|c|c|c|}
\hline (TAM) & Research Variables & $x$ & $x-\mu$ & $(x-\mu)^{2}$ \\
\hline EV & Mobile phone use & 0.84 & 0.21233 & 0.04509 \\
\hline \multirow[t]{2}{*}{ PEOU } & Time with phone & 0.86 & 0.23233 & 0.05398 \\
\hline & Education & 0.77 & 0.14233 & 0.02026 \\
\hline \multirow[t]{2}{*}{ PU } & GPS Aware & 0.844 & 0.21633 & 0.04680 \\
\hline & Phone has GPS & 0.717 & 0.08933 & 0.00798 \\
\hline Attitude (A) & Travel & 0.884 & 0.25633 & 0.06571 \\
\hline BI & Ask Direction & 0.413 & -0.21467 & 0.04608 \\
\hline \multirow[t]{15}{*}{$\mathrm{AU}$} & Find Location & 0.101 & -0.52667 & 0.27738 \\
\hline & Use GPS & 0.22 & -0.40767 & 0.16619 \\
\hline & $\sum \mathrm{x}$ & 5.649 & & 0.72946 \\
\hline & Sample Size (n) & 9 & & \\
\hline & $\bar{x}$ & 0.628 & & \\
\hline & Standard Deviation $(\sigma)$ & 0.30196 & & \\
\hline & Standard Error $(\varepsilon)$ & 0.10065 & & 0.17091709 \\
\hline & Degree of freedom & $n-1$ & 8 & \\
\hline & 95\% Confidence Level & & & \\
\hline & Error margin & 0.23805 & & \\
\hline & $\bar{x}-\mu$ & -0.3179 & \multicolumn{2}{|c|}{ Left tailed distribution curve } \\
\hline & Population Mean $(\mu)$ & 0.30976 & & \\
\hline & $\mu$ & 0.38962 & & \\
\hline & $\mu$ & 0.86572 & & \\
\hline & \multicolumn{2}{|c|}{$0.390 \leq \mu \leq 0.866$} & & \\
\hline
\end{tabular}




\section{Discussion}

\subsection{Quantitative Analysis of Mobile Phone Users}

The sample population captures $92 \%$ respondents from Kenya distributed from various counties apart from Nairobi. With about $1 \%$ of the respondents coming from out of the country, namely from Uganda and Rwanda. Nairobi as study area constituted $43 \%$ of sample population, thus $57 \%$ was Generated Population (GP) where this GP are non-Kenyan, Kenyan from other counties and those who did not respond as shown in Figure 30. The GP may have been due to the central nature of the study area in terms of Transportation, commercial, industrial, and administrative hub. The Sample population may not be fully representative of the study area population, but it captures the intentions of this research study in navigation issues with location based services, providing a much needed feedback as sample population has potential need for location and direction seeking.

From the respondents we note that the ratio of female to male is approximately $1: 4$ which is significantly different from the population with ratio $1: 1$ as in Figure 31 [49]. This indicator that less female participated in the survey as compared to their male counterparts. The anomaly would be either out of biasness from the survey assistants or lack of willingness from female participants to

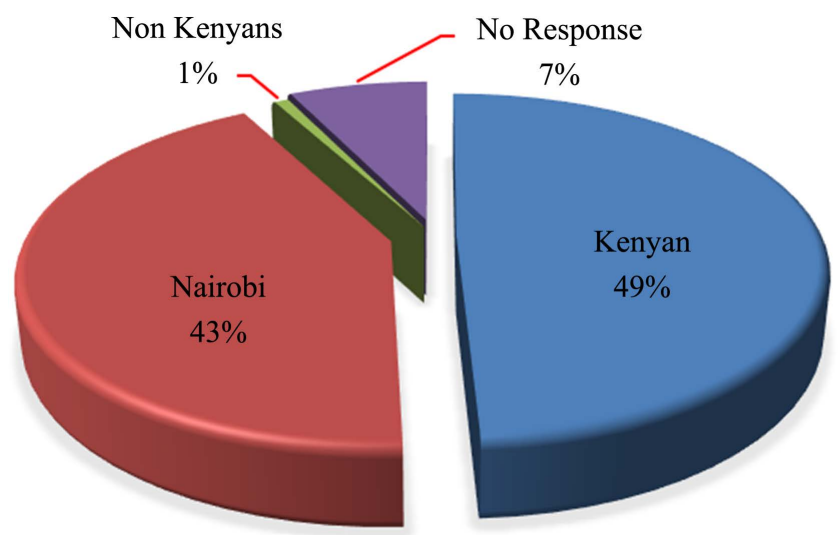

Figure 30. Respondents' residential address.

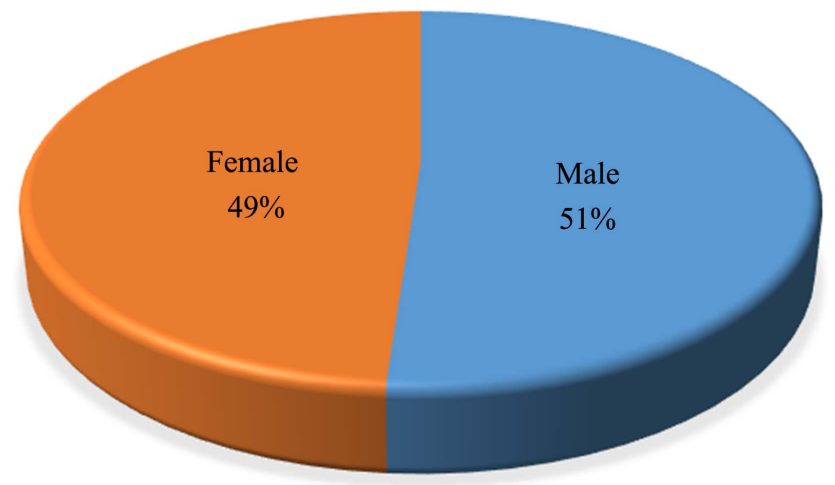

Figure 31. Proportion female to male ratio (Census 2009, KNBS). 
take part in the survey. The study had deliberately engaged survey assistants based on gender at a ratio of 1:1 to eliminate any kind of biasness in terms of interaction with participants. Low female participation may be attributed to lack of tolerance for any discussion or interruption on one's activity and also not being ready to divulge information one may not be ready to especially personal details within the questionnaire.

The respondents were from ages 15 years to 54 years, this also raises questions on why not from 0 year of age to over 80 years. This would appear so as we know that from infancy to 3 years of age is a population which requires home based care, school going children start from 3 years all the way to about 13 years and 14 years in lower and upper primary education. This bracket of the population is also directly under the care of parents or guardians and may not be allowed to have mobile phones. It is also a known fact that in learning institutions especially primary and secondary, mobile phones are prohibited and at the same time this population is totally controlled in terms of their movements by parents, guardians, and schools' administration. Hence appearing in any public place on a working day when they are supposed to be in class is difficult. It is also indicative from the respondents that the number of respondents aged 15 years to 19 years is small, this is still the age group engaged with their studies and will be difficult to encounter in public places during working days especially during academic calendar. Equally there was a big population cut out of the survey from ages 55 to over 80 years, this bracket falls in the retirement bracket and may not be busy commuting for goods and services within the city. The survey captured the active age group, which is still in active service of nation building, the category of population which is productive to the country's economic activity and carrying out their daily business around and within the city. This could have contributed to low sample mean age of 27 years as compared to about 30 years for the population data from age 15 years. This is because a big number of youths of age 20 - 30 years embrace new technologies and are in possession of mobile phones. The results also show a big section of respondents falling within ages 20 - 54 years, who are presumably in a category perceived to be financially stable mostly in employment or active business and able to meet the expense of mobile phones. This young population has a great need to communicate, do business in a more efficient and effective ways, and source for goods and services in a more efficient ways and hence do everything possible to have or acquire mobile phones to ease their efforts. From age 30 years, the number of respondents decreases tremendously towards age 54 years. This reflects the population of Nairobi as the elderly dwindle in numbers from retirement age of 55 years onward to over 80 years.

The distribution curve for both population and sample population as from age 15 years and above are unimodal and have similarities with positive skewness and positive kurtosis. With sample population having a mean of 27.8 years, a mode of 24 years and medium 25 years. Sample population is not normally distributed, and has a mean age is greater than mode age greater than median age 
hence positive skewness. Population data has a mean of 30.7 years with a mode of 25 years and median of 28 years. It has a positive skewness with mean greater than median and greater than mode, with also a positive kurtosis.

Based on census data of 2009 (KNBS), Nairobi has 70\% population accessible to mobile phones service while $21 \%$ are not accessible, $9 \%$ were not asked on the same implying either minors or incapable to have access to this service [49]. This shows that population from age 15 years to over 80 years and over who are about $2,187,366$ out of the total population of $3,138,369$ comprise $70 \%$ of the entire population and are supposedly in possession of mobile phones leaving out the minors at $30 \%$ who may not or have controlled access to these services.

The impression that mobile phones are enslaving users was tested by the duration the gadget is in contact with its user in the day. This seems to be true, as about $69 \%$ of respondents are in possession of mobile phone for over $12 \mathrm{hrs}$ which is a better part of their active daily time with about $19 \%$ who have it from $8 \mathrm{hrs}$ to 12 hours. This highlights over dependency on mobile phones, a confirmation of over dependence to this device. It is a general opinion that many feel disorganized, useless, wasted time and lost-out among many other feelings on not having the mobile phone especially if just forgotten at home or lost.

Popularity of mobile phone technology can be noticed through its choice as most preferred form of media for information transmission and dissemination at $89.2 \%$ rating as most used, followed a distance second by Computer \& Internet at $55.9 \%$ rating, Television at $53.7 \%$ and Radio at $46.4 \%$. The worst being letters with a rating of $2 \%$ as most used median. Newspaper and Landline Telephone have $22.7 \%$ and $22.5 \%$ respectively, just reinforcing the fact on usefulness of mobile phones. This also emphasizes on the technological advances in information transmission and dissemination and the need to have smaller and portable devices that can assist human in many ways but consolidated in one piece through this digital age. With its rapid growth in acceptance, mobile phone has become a platform where many applications solving many tasks are being loaded to.

The mobile phones are not any cheap, but the population which is accessible to the service can just give an impression of worthiness and importance of these gadgets to users. Functionality, Smartphone, brand apart from cost are among features considered on acquiring of mobile phones, putting applications such as GPS and LBS in the fore just amongst those that are exposed to respondents' efficacy indicating respondents' itch for new technology.

From previous studies it is evident that growth of mobile phone in Kenya had been exponential starting from 1999 where the population using mobile phones was 15,000 to 2009 were those with mobile phones went above 17,000,000 and over 20,000,000 in 2019 as indicated in Figure 32. This is an indicator of popularity mobile technology has received from consumers in this part of the world. This also supports preference by respondents' selection of mobile phone as the best in information transmission delivery and distribution. 


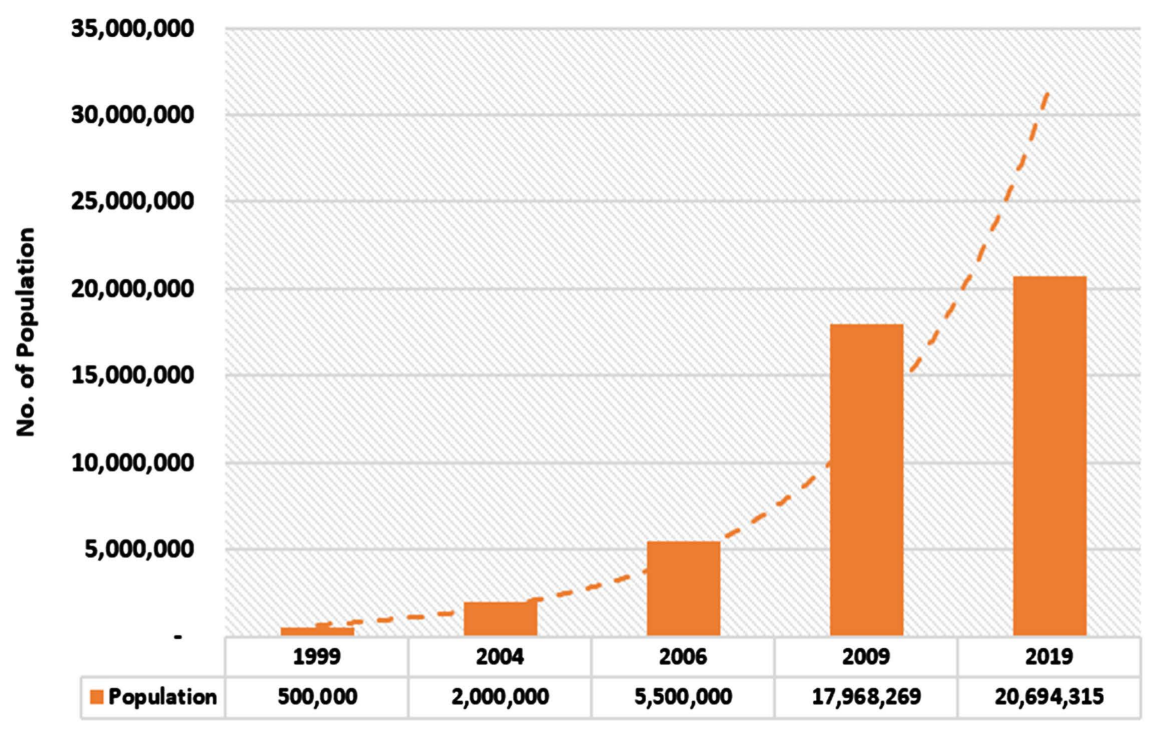

Figure 32. Mobile phone growth in Kenya.

\subsection{Personal Habits}

Travel, enquiry on directions and time are just among the many habits that you would get from a common population. It was apparent that for those respondents who indicated that they always/often/sometimes travel were about $88 \%$, and those who always/often/sometimes inquire on direction were $59 \%$ while those always/often/sometimes inquire on time of day were $57 \%$. It may be presumed that $29 \%$ from the $88 \%$ who travel either travel within familiar areas or may be using the technology to access their areas of travel or destinations as they do not enquire for directions. That is such a small number bearing in mind on the hype LBS technology has received so far. It is evident from the study that a small percentage of respondents use this technology despite having prior knowledge of its existence, hence underlying issues that does not attract them to it. These are challenges that need to be addressed to alter the unwillingness to adopt this technology at hand.

\subsection{LBS Awareness and Usage}

Mobile phone is a hardware that hosts various applications, which assist users with a variety of tasks in real life. Among the applications are internet access, sms service, voice call, calculator, clock, navigation applications, GPS, documentation and filing applications among others. Internet access, clock and SMS service were rated highly with "Find location" a navigational application which belongs to LBS family, was rated low as always used on a Likert scale of always used to never used. Bearing in mind predictions and hype exhibited towards these applications, this indeed is below expected usage levels. Judging from high numbers of users who seek for direction, a marginal number on usage depicts low rating on acceptability and adoption on use of this technology for direction and location seeking. Marginal use of this technology indicates some underlying 
issues or challenges which need to be addressed within this part of the world to promote acceptance. The user needs to be relooked at and solutions determined for its growth. It is also clear that a huge number of respondents were aware of GPS functionality on their mobile phone and were knowledgeable about the functionality but did not use it as part of their solution to find direction to new places of visit was evident by a small percentage of respondents who always/often/sometimes use GPS functionality with a big number that had rarely or never used GPS functionality.

A big majority of respondents being well educated having attained secondary education and above, could have embraced new emerging technologies hence sophisticated applications with the use of mobile phone would not be a challenge for most of them. LBS technology is thereby not a challenge, the only challenge would be on what information they get and how do they get it. They do also understand very well what LBS and the connection to GPS and what can be obtained from these technologies.

It is noted that female majority may not mind locating their position as opposed to male counterparts where majority are opposed to their location being determined by the fact of GPS functionality determining the position of the mobile phone on the earth surface. This clearly infringes in a user's privacy which is never taken lightly by many. They would have varying reason as to why one would have their location private. Many respondents did not respond to this question creating an impression that they may be confused on that matter, as much as it is important to find location it would be equally detrimental to determine their position if a third party is to have the same.

\subsection{Data Reliability}

The participants came from a wide range of addresses as far as Uganda and Rwanda which are neighbouring countries, others coming from other counties scattered across the country including Nairobi County. A large set of the sample population came out of the study area which had not been the intention of the research study. This also implies that the sample population was not a true representation of subject population. This sights weakness in sampling method adopted in the study as it introduced generated population. This can be attributed to the nature of sample area, Nairobi CBD being a transit point of travel and a commercial center, it attracts other population from elsewhere. A large percentage came from the sample area whereas outliers were distributed throughout the country. This generated population could be attributed to people seeking goods and services within this administrative and commercial centre. The intention of this study was not dampened though as this still formed the travellers who are potential GPS and hence LBS users. Since some respondents were not from within, this revelation throws doubt in the external reliability of this survey, as whether it is representative of subject population in Nairobi County, thereby giving a lesson on sampling procedures that may be relevant in 
such circumstances were sample population must be representative of the subject population.

With the expectation of approximately equal numbers of female to male, huge discrepancy was witnessed in the sample population that throws doubt in reliability of the collected sample data. Either the choice of area earmarked for questionnaire distribution did not have a balance between female and male, presuming that the male form the largest labour force for this region or female counterparts just lacked interest in participating in this survey. As much as this notion can be dispelled away as this research study engaged survey assistants by gender at ratio of 1:1 female to male. The interaction of all survey assistants was consistent with similarity pattern on female to male ratio outreach of approximately 1:6 at worst to $2: 5$ at best, the information was consistence and hence acceptable for evaluating mobile phone and LBS accessibility.

The sample population had a mean age of 27.5 years, sample standard deviation of 7.6 years and sample standard error of 0.4808 a sample size of 251 respondents who provided information about their age. At varying confidence levels, the population mean as for data from ages 15 years and above was 30 years as indicated in Figure 33, which does not fall within the outlined margins. This presents doubt to whether the sample population characterizes the population and hence doubt on reliability of data this is as outlined in Table 6 .

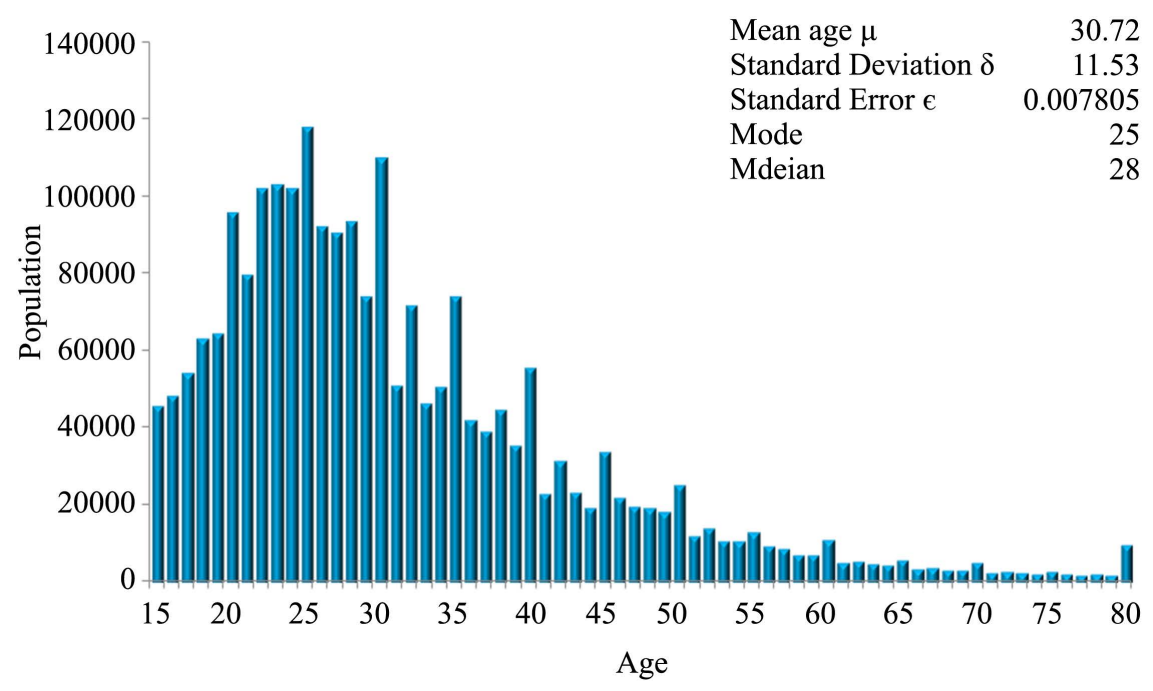

Figure 33. Nairobi population ages 15 years and above.

Table 6. Variation of mean at different confidence level.

\begin{tabular}{cccc}
\hline CL & z-value & Margin of Error & Mean Range \\
\hline $95 \%$ & 1.96 & 0.942368 & $26.6 \leq \mu \leq 28.4$ \\
$98 \%$ & 2.33 & 1.120264 & $26.4 \leq \mu \leq 28.6$ \\
$99 \%$ & 2.58 & 1.240464 & $26.3 \leq \mu \leq 28.7$ \\
$\mathbf{1 0 0 \%}$ & 3.99 & 1.918392 & $25.6 \leq \mu \leq 29.4$ \\
\hline
\end{tabular}


The time for data collection had been scheduled for a working day, from Monday to Friday which is ideal for it is a business day where business people and service providers are on the move in and out of the sample area. In consideration of a stratified sampling method, this would have required visiting residential areas of the city which should have been ideal on a weekend or Sunday alone that would have taken quite a long time in data collection, and it would have been expensive to mobilize.

\subsection{Validity Test}

The survey data enable the research intention of evaluating mobile phone users on location-based services and GPS functionality on their phones, as much as the data did not represent the population intended $100 \%$. But the data was good enough in that it was able to provide a measure that was used to evaluate on usage of LBS technology in this region. It is from this survey that it is apparent that LBS technology has not fully been embraced as earlier predicted from different journal papers. The technology is not in use even to those who are aware of its existence, pointing at underlying concerns about the technology. The approach was based on identifying Nairobi as a study area, with consideration of the population in it based on census data of 2009. There was ease in accessing the study area from our institution of learning hence less cost on mobilization and it being densely populated implying easy interaction with sample population. The choice of sample area was Nairobi CBD with an intention to have a simple random sampling method adopted for the sake of cost and time to carry out field survey.

LBS applications are among many applications hosted on mobile phone, this technology had been anticipated to grow momentously with popularity of finding location habits of users in search of services and touring. To evaluate on LBS technology the research study enquired on travel habits of users, association of finding direction and whether users utilize their mobile phones towards such challenges. This formed a basis for evaluation on acceptance and usability of this technology, linked to population accessible to mobile services as captured by population census 2009 (KNBS) [49].

From the analysis it is possible to conclude that similar findings can be replicated within this region and that signifies an underlying problem that needs to be addressed where solution could improve on this technology. As much as at 99\% confidence level, the mean of the population does not agree falling off margin of error, data distribution between sample population and the population shows some similarities with unimodal graph which are positively skewed with positive kurtosis.

\subsection{Technology Acceptance Model (TAM)}

In ideal situation should score 1.0, except for enquiring for direction which should be 0.0 at its best, LBS usage and worst scenario being 1.0. For this study 
"ask for direction" was given by 1-score, as an entry for acceptance and adoption assessment this being shown in Table 6. The variables are treated as sample data where mean, standard deviations are used to compute proportion on acceptance level based on questionnaire variables observed. At 95\% confidence level the mean, based on observed variables and considering a T-distribution left hand tailed distribution curve as presented in Figure 34 should be 0.44045 (44.05\%) acceptance level.

It is evident that Actual Use (AU) score mean was 0.161, whereas the TAM variable mean is 0.441 and at $95 \%$ confidence level mean can vary from 0.390 to 0.866 as acceptable level of acceptance on the LBS technology, hence AU falls below acceptable value.

\subsection{Hypothesis Testing}

Null hypothesis states that the mean of Actual Use (AU) should be greater than mean of TAM variables, while alternate hypothesis state that mean of AU should be less than TAM mean.

$$
\begin{aligned}
& H_{0}: \mu \geq 44.05 \%(0.4405) \\
& H_{a}: \mu<44.05 \%(0.4405)
\end{aligned}
$$

As such the predicted growth in LBS technology would have meant that AU mean should be greater than the value of TAM mean, and therefore AU of 0.161 falls short of the null hypothesis as it is less than TAM mean of 0.4405 and agrees with the alternate hypothesis.

This annuls the hypothesis that "the LBS growth would be rapid or be at high levels globally, in the contrary this part of the world it is not true as this research study reveal low actual usage of the technology, implying that LBS technology has not been accepted and adopted in this region as expected.

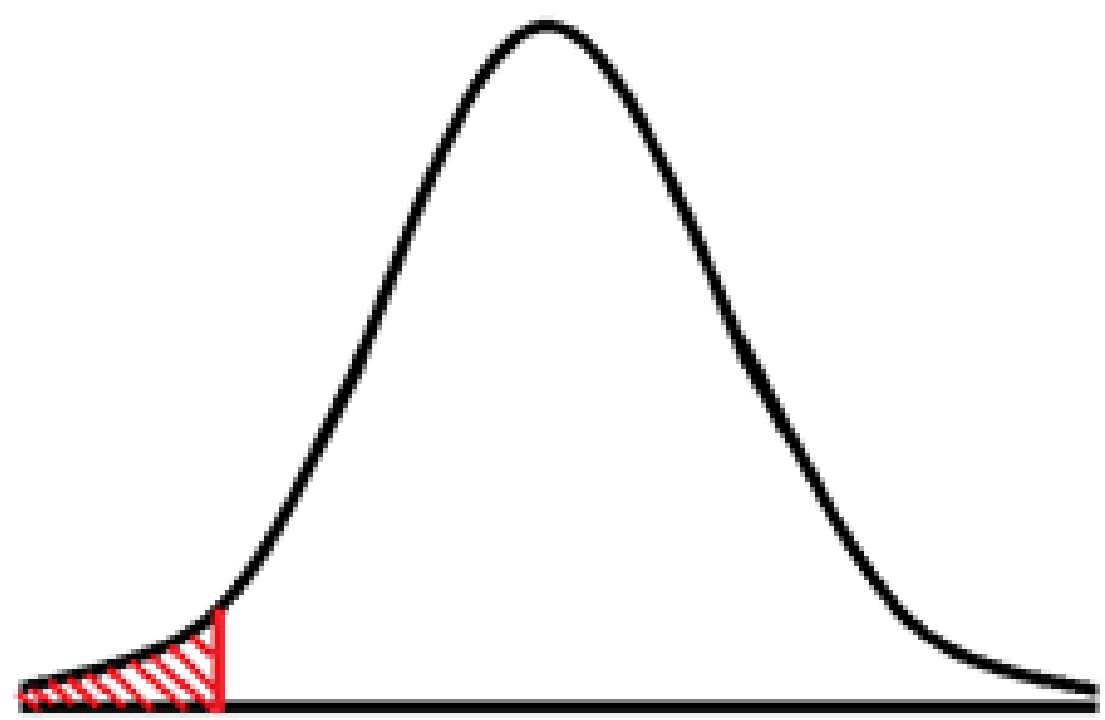

Figure 34. Left tail T-distribution curve. 


\section{Conclusions and Recommendations}

\subsection{Remarks}

- From the study LBS technology has not grown to acceptable levels, hence adoption of this technology is below expectation contrary to earlier predictions from previous studies, as much as awareness and knowledge on it exist.

- Mobile phone service that is hosts to LBS among other applications is most preferred as the medium of information and communication within this region and clearly indicating to take users hostage by being hocked to it.

- As early as 15 years of age they own mobile phones, indicating permeation of mobile phony in even the young population for the sake of communication and information dissemination.

- For a quantitative survey using a questionnaire, a self-interactive, simple, brief and easy to respond to questionnaire as an instrument guarantee a huge response outcome that provides ample data that can be used for analysis in such a research exercise, which also saves on time and cost for research activity through simple random sampling method.

- Technology acceptance model can be applied to provide a simple means of evaluating and assessing emerging technology adoption-based variables relationship creation (VRC) of the study and TAM.

\subsection{Recommendations}

- Deliberate effort should be made to monitor and evaluate new and emerging technologies based on consumer acceptance and adoption to prove relevance for technologies and challenges that may exist. This shall enhance innovations on such technologies through research activities for sustenance growth based on user satisfaction and utilization, where technology acceptance method (TAM) can be applied.

- In similar quantitative studies, sampling method and choice of sample area would require adopting a more accurate method that does not allow generated population (GP) outside of the study area as it may give a different characteristic of the sample population. The use of stratified sampling method which represents regions within divergence environment would work well for such a region as Nairobi to capture the general characteristics of the population as compared to simple random sampling method at a specifically chosen location. This affects reliability of sample population as it may not fully represent the population in question.

\section{Acknowledgements}

I wish to extend my special thanks to my supervisors Prof. E. H. Waithaka, Prof. M. K. Gachari and Prof. D. N. Kuria for their guidance, support, and patience. I equally give a lot of gratitude to my beloved Wife for her encouragement, moral 
and material support. I also express my sincere appreciation to Jomo Kenyatta University of Agriculture and Technology for sponsoring my research work.

\section{Conflicts of Interest}

The authors declare no conflicts of interest regarding the publication of this paper.

\section{References}

[1] Wang, Y.S., Lia, H.T., Lib, C.R. and Zhang, D.Z. (2016) Factors Affecting Hotels' Adoption of Mobile Reservation Systems: A Technology-Organization-Environment Framework. Tourism Management, 53, 163-172. https://doi.org/10.1016/j.tourman.2015.09.021

[2] Shuman, M.A. and Ansari, Y. (2013) System for Multimedia Tagging by a Mobile User. USA Patent US8447324B2.

[3] Cooper, C.W.R. and Wallner, A.M. (2019) System and Method of Wireless Down-Loads of Map and Geographic Based Data to Portable Computing Devices. United States Patent US 10244361B1.

[4] Abdalla, R. (2016) Mobile GIS and Location-Based Services (LBS). In: Introduction to Geospatial Information and Communication Technology (GeoICT), Springer, Cham, 83-103. https://doi.org/10.1007/978-3-319-33603-9 5

[5] Gao, S. and Mai, G. (2018) Mobile GIS and Location-Based Services. In: Huang, B., Cova, T.J., Tsou, M.-H., et al., Eds., Comprehensive Geographic Information Systems, Vol. 1, Elsevier, Oxford, 384-397. https://doi.org/10.1016/B978-0-12-409548-9.09710-4

[6] Bao, Z., Gao, Y., Gu, Y., Guo, L., Li, Y., Lu, J., Zujie, R., Wang, C. and Zhang, X. (2012) Web-Age Information Management. WAIM 2012 International Workshops. GDMM 2012, IWSN 2012, MDSP 2012, USDM 2012, and XMLDM 2012, Harbin, China, August 18-20 2012.

[7] Keeler, J.D. (2016) Providing Location-Based Services in a Distributed Environment without Direct Control over the Point of Access. United States Patent US9529854B2.

[8] Peng, T., Liu, Q. and Wang, G. (2017) Enhanced Location Privacy Preserving Scheme in Location-Based Services. IEEE Systems Journal, 11, 219-230. https://doi.org/10.1109/JSYST.2014.2354235

[9] Zhang, Y.L. and Wang, X.K. (2017) LBS Mobile Learning System Based on Android Platform. ITM Web of Conferences, 11, Article No. 10005.

[10] Khalajzadeh, H., Abdelrazek, M., Grun, J., Hosking, J. and He, Q. (2018) A Survey of Current End-User Data Analytics Tool Support. 2018 IEEE International Congress on Big Data (BigData Congress), San Francisco, 2-7 July 2018, 41-48. https://doi.org/10.1109/BigDataCongress.2018.00013

[11] Hu, P.J., Chau, P.Y.K., Liu Sheng, O.R. and Yan Tam, K. (1999) Examining the Technology Acceptance Model Using Physician Acceptance of Telemedicine Technology. Journal of Management Information Systems, 16, 91-112. https://doi.org/10.1080/07421222.1999.11518247

[12] Luo, H., Bedolla, J. and Chao, Y.-C. (2017) Hybrid Navigation System with Location Based Services and Method of Operation Thereof. United States Patent US9541402B2.

[13] Vissa, S.C., Nasti, J.V., Tyagi, V.K. and Lautner, D.A. (2019) Navigation Tracking in an Always Aware Location Environment with Mobile Localization Nodes. WIPO 
Patent No. 10433118.

[14] Zadeh, A.H., Zolbanin, H.M. and Shard, R. (2018) Social Media for Nowcasting Flu Activity: Spatio-Temporal Big Data Analysis. Information Systems Frontiers, 21, 743-760. https://doi.org/10.1007/s10796-018-9893-0

[15] Coleman, D.J., Rajabifard, A. and Kolodzi, K.W. (2016) Expanding the SDI Environment: Comparing Current Spatial Data Infrastructure with Emerging Indoor location-Based Services. International Journal of Digital Earth, 9, 629-647. https://doi.org/10.1080/17538947.2015.1119207

[16] Yang, G., Luo, S., Zhu, H., Xin, Y., Li, M. and Wang, Y. (2019) An Efficient Approach for LBS Privacy Preservation in Mobile Social Networks. Applied Sciences, 9, Article No. 316. https://doi.org/10.3390/app9020316

[17] Chakraborty, P. and Shah, A. (2018) Interactive Touch Screen Using Augmented Reality. 2018 4th International Conference on Applied and Theoretical Computing and Communication Technology (iCATccT), Mangalore, 6-8 September 2018, 294-298. https://doi.org/10.1109/iCATccT44854.2018.9001956

[18] Cheruvu, S., Kumar, A., Smith, N. and Wheeler, D.M. (2020) Connectivity Technologies for IoT. In: Demystifying Internet of Things Security, Apress, Berkeley, 347-411. https://doi.org/10.1007/978-1-4842-2896-8 5

[19] Rajapakse, R. and McIntosh, I.M. (2017) System for Synchronous Playback of Media Using a Hybrid Bluetooth ${ }^{\mathrm{TM}}$ and Wi-Fi Network. United States of America Patent No. US20170019197A1.

[20] Chopra, K., Gupta, K. and Lambora, A. (2019) Future Internet: The Internet of Things-A Literature Review. 2019 International Conference on Machine Learning, Big Data, Cloud and Parallel Computing (COMITCon), Faridabad, 14-16 February 2019, 135-139. https://doi.org/10.1109/COMITCon.2019.8862269

[21] King, G. and Tiley, S. (2019) System, Method, and Computer Program Product for Connecting or Coupling Audio Communications Systems over a Software Defined wide Area Network. United States of America Patent US9986101B2.

[22] Toskala, A., Nakamura, T. and Holma, H. (2019) 5G Technology: 3GPP New Radio, John Wiley \& Sons, Inc., Hoboken, New Jersey.

[23] Koohikamali, M., Mousavizadeh, M. and Peak, D. (2019) Continued Usage and Location Disclosure of Location-Based Applications: A Necessity for Location Intelligence. Proceedings of the 52nd Hawaii International Conference on System Sciences, Hawaii, 8-11 January 2019, 1362-1372.

https://doi.org/10.24251/HICSS.2019.166

https://scholarspace.manoa.hawaii.edu

[24] Shirani, A. and Sehhati, M. (2019) Design and Implementation of a Customable Automatic Vehicle Location System in Ambulances and Emergency Vehicle Systems. Journal of Medical Signals and Sensors, 9, 165-173.

https://doi.org/10.4103/jmss.JMSS 41_18

[25] Tariq, H., Tahir, A., Touati, F., Abdulla, M., Al-Hitmi, E., Crescini, D. and Adel Ben Manouer, A.B. (2019) Geographical Area Network-Structural Health Monitoring Utility Computing Model. ISPRS International Journal of Geo-Information, 8, Article No. 154. https://doi.org/10.3390/ijgi8030154

[26] Hakola, P. (2009) Macro Diversity Combining Optimization in HSPA Flat Architecture. Master's Thesis, Helsinki University of Technology, Espoo, 73. http://urn.fi/URN:NBN:fi:aalto-201203071281

[27] Mohmad Umair, B. and Thangadurai, N (2019) Embedded System Interfacing with 
GNSS User Receiver for Transport Applications. International Journal of Advanced Computer Science and Applications, 10, 300-308. https://doi.org/10.14569/IJACSA.2019.0100939

[28] Garg, D. and Shukla, A. (2013) GEO ALERT - A Location Based Alarm System Using GPS in Android. International Journal of Multidisciplinary in Cryptology and Information Security, 2, 11-14.

[29] Deidda, M., Pala, A. and Vacca, G. (2013) An Example of a Tourist Location-Based Service (LBS) with Open-Source Software. Applied Geomatics, 5, 73-86. https://doi.org/10.1007/s12518-012-0097-X

[30] Huang, H., Gartner, G., Krisp, J.M., Raubal, M. and Van de Weghe, N. (2018) Location Based Services: Ongoing Evolution and Research Agenda. Journal of Location Based Services, 12, 63-93. https://doi.org/10.1080/17489725.2018.1508763

[31] Basiri, A., Moore, T., Hill, C. and Bhati, P. (2016) The Non-Technical Challenges of Location Based Services Markets: Are the Users' Concerns Being Ignored? 2016 International Conference on Localization and GNSS (ICL-GNSS), Barcelona, 28-30 June 2016, 1-5. https://doi.org/10.1109/ICL-GNSS.2016.7533866

[32] Narasimha, M., Berdinis, E., Kim, S.S. and Robert, T. (2018) Method and Apparatus for Operating a User Client Wireless Communication Device on a Wireless Wide Area Network. United State of America Patent US20160227410A1.

[33] Maitai, J. and Omwenga, J.Q. (2016) Factors Influencing the Adoption of Mobile Money Transfer Strategy in Telecommunication Industry in Kenya: A Case of Safaricom-Kenya Ltd. IOSR Journal of Business and Management, 18, 84-94.

[34] Muchai, D.N. and Kimuyu, P. (2018) ICT Enabled Services: The Case of Mobile Money Transfer in Kenya. https://wider.unu.edu

[35] Bosire, J.M. and Ntale, J.F. (2018) Effect of Mobile Money Transfer Services on the Growth of Small and Medium Enterprises in Informal Sector of Nairobi County, Kenya. International Journal of Information Research and Review, 5, 5326-5333.

[36] Angelova, N. (2019) Mobile Applications for Business. Trakia Journal of Sciences, 17, 853-859. https://doi.org/10.15547/tjs.2019.s.01.140

[37] Taherdoost, H. (2018) A Review of Technology Acceptance and Adoption Models and Theories. Procedia Manufacturing, 22, 960-967.

https://doi.org/10.1016/j.promfg.2018.03.137

[38] Lai, P.C. (2017) The Literature Review of Technology Adoption Models and Theories for The Novelty Technology. Journal of Information Systems and Technology Management, 14, 21-38.

[39] Rogers, E.M. (2002) Diffusion of Preventive Innovations, Addictive Behaviors, 27, 989-993. https://doi.org/10.1016/S0306-4603(02)00300-3

[40] Goodhue, D.L. and Thompson, R.L. (1995) Task-Technology Fit and Individual Performance. Management Information Systems Research Center, University of Minnesota, 19, 213-236. https://doi.org/10.2307/249689

[41] Fishbein, M. and Ajzen, I. (1975) Belief, Attitude, Intention, and Behavior: An Introduction to Theory and Research. Addison-Wesley, London.

[42] Ajzen, I. (1985) From Intentions to Actions: A Theory of Planned Behavior. In: Kuhl, J. and Beckmann, J., Eds., Action Control, Springer, Berlin, 11-39. https://doi.org/10.1007/978-3-642-69746-3 2

[43] Ajzen, I. (1991) The Theory of Planned Behavior. Organizational Behavior and Human Decision Processes, 50, 179-211. https://doi.org/10.1016/0749-5978(91)90020-T 
[44] Taylor, S. and Todd, P. (1995) Decomposition and Crossover Effects in the Theory of Planned Behavior: A Study of Consumer Adoption Intentions. International Journal of Research in Marketing, 12, 137-155. https://doi.org/10.1016/0167-8116(94)00019-K

[45] Davis, F.D., Bagozzi, R.P. and Warshaw, P.R. (1989) User Acceptance of Computer Technology: A Comparison of Two Theoretical Models. Management Science, 35, 982-1003. https://doi.org/10.1287/mnsc.35.8.982

[46] Venkatesh, V. and Davis, F.D. (2000) A Theoretical Extension of the Technology Acceptance Model: Four Longitudinal Field Studies. Management Science, 46, 169-332. https://doi.org/10.1287/mnsc.46.2.186.11926

[47] Venkatesh, V. and Bala, H. (2008) Technology Acceptance Model 3 and a Research Agenda on Interventions. Decision Sciences, 39, 273-315.

https://doi.org/10.1111/j.1540-5915.2008.00192.x

[48] Braun, M.T. (2013) Obstacles to Social Networking Website Use among Older Adults. Computers in Human Behavior, 29, 673-680. https://doi.org/10.1016/j.chb.2012.12.004

[49] Kenya Government (2010) The 2009 Kenya Population and Housing Census. Kenya National Bureau of Statistics, Nairobi.

[50] Kenya Government (2019) 2019 Kenya Population and Housing Census. Kenya National Bureau of Statistics, Nairobi.

[51] Karani, G. (2019) Universal Design Awareness among Urban Planners and Its Impact on Public Transport Systems in Nairobi, Kenya. Africa Habitat Review, 13, 1627-1633. http://erepository.uonbi.ac.ke/handle/11295/155027 